\title{
LITERATURE AND COGNITIVE SCIENCE
}

\author{
ALEX JOHNSON
}

A THESIS SUBMITTED

IN PARTIAL FULFILMENT OF THE REQUIREMENTS FOR

THE DEGREE OF MASTER OF ARTS

Victoria University of Wellington, 2012 
1) P a g e 


\begin{abstract}
:
The field of Literature and Cognitive Science is an emergent one. This thesis investigates ways in which knowledge generated about the brain and mind in the field of Literature can complement knowledge generated about the brain and mind in the field of Cognitive Science. The work of a representative selection of literary critics who identify themselves as working within and shaping the field of Literature and Cognitive Science will be examined, and the representation of brain-mind states in two contemporary novels, Haruki Murakami's Hard-Boiled Wonderland and the End of the World and Pat Cadigan's Tea from an Empty Cup, will be closely analysed. A principal aim of this investigation is to affirm the power of literary and literary critical texts as potent and relevant knowledge sources about the brain and mind that must be included in our understanding of cognition. In this respect it will support the position of those in the field of Literature and Cognitive Science who argue that knowledge created in the field of Literature can enrich the new understanding of human cognition being developed in the field of Cognitive Science.
\end{abstract}




\section{TABLE OF CONTENTS}

INTRODUCTION

PAGE 4

\section{CHAPTER 1}

The Field of Literature and Cognitive Science....................................................... 6

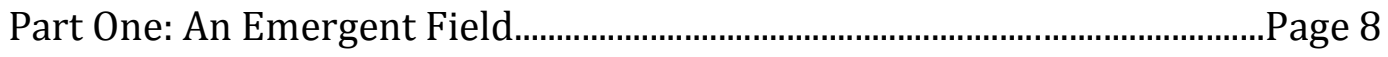

Part Two: What does Cognitive Science have to offer Literature?............Page 10

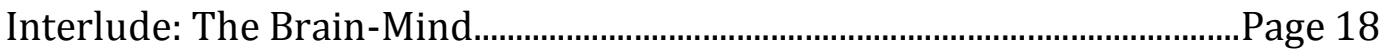

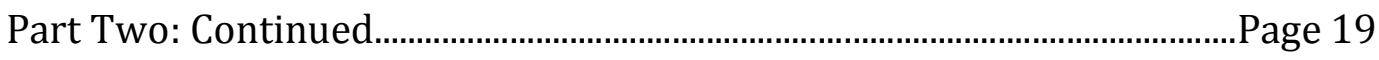

Part Three: What does Literature have to offer Cognitive Science?.........Page 27

Part Four: What further? Critique as Middle Ground..................................Page 33

\section{CHAPTER 2}

Prelude Page 37

Part One: Modeling the Brain-Mind. Page 39

Part Two: Interaction of Spaces. Page 54

Part Three: The Brain-Mind as Affected By and Affecting

Culture and Society Page 60

\section{CHAPTER 3}

Critique. Page 70

CONCLUSION

Page 82 
INTRODUCTION:

Science has become the way in which we understand the world. The process that any scientific endeavour undergoes is based on repeatable observation and is processed through a method which gives a very specific kind of formal knowledge about the world we inhabit. Cognitive Science is an umbrella term that encompasses all those scientific endeavours that seek knowledge about the cognitive processes: as technology has lately provided tools that can provide repeatable observation on the workings of a brain as an agent is cognitively aware, the sciences are now able to produce knowledge about the brain through their method in a way which is qualitatively and quantifiably different to the ways in which knowledge about the brain and the mind was previously generated by processes within the traditions of theology, philosophy, and criticism, which we will be particularly concerned with as it acts upon such artefacts as literary narrative.

Literary criticism and the interpretation of literary narrative, called in this thesis the field of Literature, creates formal knowledge in a distinctly different way to that which is undertaken by science. The main aim of this thesis is to begin an investigation into the ways in which the knowledge generated about the brain and mind by the field of Literature can or does interact with the knowledge generated about the brain and mind by science: knowledge generated by that which is called Cognitive Science. To accomplish this aim, this thesis will contain three chapters, the first in which a representative selection of critics from the humanities who are also concerned with the interaction of knowledge produced by the two fields will be discussed in order to start tracing the extent and qualities of the field called Literature and Cognitive Science. A process of interpretation which is informed by the examination of the existing field will then be performed in the second chapter on two instances of literary narrative, Haruki Murakami's Hard-Boiled Wonderland and 
the End of the World ${ }^{1}$ and Pat Cadigan's Tea from an Empty Cup, ${ }^{2}$ in order to provide evidence for and examine the claims produced by the first chapter. The third chapter will continue the examination between the evidence generated by the interpretation performed on the novels and the critical work of the first chapter with the particular aim of discovering what emphasis and importance literary narrative and the field of Literature should be given in the process of examining the interaction between Literature and Cognitive Science. At its conclusion, this thesis hopes to affirm the power of Literature not just as evidence for the knowledge generated by the processes of Cognitive Science, but as a process that itself generates potent and relevant knowledge about the brain and mind that must be included in our understandings of cognition, and be given specific importance in the field of Literature and Cognitive Science. This thesis will therefore be not only an examination of the emergent field of Literature and Cognitive Science but also a piece of work that both orientates myself with that field of study and a critique that generates discussion around how that field may be developed in the future.

1 Murakami, Haruki. Hard-Boiled Wonderland and the End of the World. London: Vintage, 2003

2 Cadigan, Pat. Tea from an Empty Cup. New York: Tom Doherty Associates, 1998.

$\mathbf{5}$ |P a g e 
CHAPTER ONE:

THE FIELD OF LITERATURE AND COGNITIVE SCIENCE

Literature and Cognitive Science is an emergent field of enquiry. Between Literature, the field of literary criticism and interpretation which acts upon literary narrative or novelistic fiction, and Cognitive Science, those sciences actively engaged with the study of cognition within which are included the fields of psychology, neuroscience and cybernetics, complex interactions take place. The critics examined in this chapter have been chosen to represent the range of approaches, interests and concerns that the field of Literature and Cognitive Science can be said to encompass. By examining Literature in relation to the concepts, ideas and innovations of Cognitive Science these critics produce interpretations of fictional texts which position themselves within the field of Literature and Cognitive Science and describe a scope of study as well as creating new models of the way in which the brain-mind behaves and is understood. Comparing these models is the aim of this chapter, as that process will create a representational account of the emergent field of Literature and Cognitive Science and provide an important framework for later interpretative action on works of novelistic fiction and serve as comparable to the models that the fictions themselves produce.

This chapter will discuss the critical writings through a selection of focusing questions in order to establish principal themes and interests in the critics' work, with the aim of providing a new and illuminating context for interpreting the novels, and ultimately leading to an interpretation that we can read the novels against. This process has been begun in varying degrees by both writers of fiction and criticism as they seek to create approaches and processes that allow mediation of ideas between the two cultures of scientific and literary discovery and examine the legitimacy of the binary pairing that places science and its empirical descriptions of reality in 
opposition to literature and fiction. Along with positioning itself in relation to these exchanges this chapter will also make the argument for narrative literature that is engaged with concerns surrounding the understanding of the brain-mind to be thought of as both partially produced in relation to the knowledge generated by Cognitive Science and recognized as contributing to the development of that knowledge.

Zunshine, in her recent collection aimed at further defining this field, ${ }^{3}$ writes that "readers, both specialist and non-specialist, are eager for a sustained conversation about literature, culture and cognition" (p.I). How this conversation can take place is a critical issue. Zunshine's own conception, endorsed in this thesis, is that "the goal of the cognitive cultural studies project... is to understand the evolving relationship between two immensely complex, historically situated systems- the human mind and cultural artefacts, such as novels, poems or paintingsand not merely to use such artefacts to illustrate a particular scientific hypothesis about one particular feature of human cognition" (p.3). Complementary accounts from the field of Philosophy of Science ${ }^{4}$ of how this conversation can take place, which affirms the essential role of critique in the discussion between the Humanities and Cognitive Science will also be considered, affirming the place of critique as essential in the discussion between Literature and Cognitive Science. Overall, this chapter will provide a prelude towards reading the novels, and a substantial unearthing of the rock and grit of the debate.

3 Zunshine, Lisa. Ed. Introducton to Cultural Cognitive Studies. Maryland: The Johns Hopkins University Press, 2010.

4 Slaby, Jan. "Steps Towards a Critical Neuroscience" 2010. 5 March, 2010. $<$ http://www.janslaby.com/pubs/Slaby StepsTowardsCNS 2010.pdf> 
PART ONE:

AN EMERGENT FIELD

The emergent character of the field of 'Literature and Cognitive Science' must be kept in the foreground. For something to be called 'emergent' it must yet still be condensing itself into its final shape, still arising from its surrounds, not yet identifiable in parts as completely discrete. This emergent property is also apparent in the Cognitive Sciences themselves where, on the one hand, developments in technology have enabled new and exciting ways to gather evidence for this branch of science, which have in turn generated the drive for more and more advanced technology, both developing at such a pace that outstrips the reflective and evaluative practices needed to deal with those advancements; on the other is the rich and problematic history that we have with the term 'cognition.' As the term 'Cognitive Science' encompasses such varying approaches as psychology, neuroscience and computational intelligence it becomes essential to remember that this is a field that has yet to have its boundaries cemented, so much so that the metaphor of this endeavour as being one that seeks inclusion into or the claiming of territory within what is already a populated and crowded conceptual landscape becomes limiting. The process by which this field is emerging and becoming defined is not a battle to carve out a niche that can then be fenced off and owned: I prefer to think of it as the looking up at the night-sky of thought and joining together the, sometimes distant, ideas to create a meaningful constellation that can aid in the making of a journey. The writers we will consider have already begun this task, and from this examining of those writers' sources of influence our own configuration of ideas will emerge. What characterising the endeavour of Literature and Cognitive Science with this metaphor of the night sky achieves is the highlighting of the usefulness of the convergences and connections between these constellations, 
decreasing the emphasis on limitations of and validity of a claim to space as a discrete body of knowledge that the metaphor of the field can imply.

Broadly, the reason that this field of enquiry is and must be considered as emergent is that the Cognitive Sciences are emergent within science as a whole. The consideration of what Literature means to Science, and vice versa, has been underway since we conceived of the ventures as separate but Cognitive Science is a, relatively speaking, new concern; but the seductive power of Cognitive Science as a source of knowledge about cognition must be acknowledged, as must the lack of authority attributed to literary explorations of the human mind. This imbalance of attributed authority between these two approaches at the very least shows the necessity of examining the cultures together, and hints towards the need for Literature to be given more attention as a mode of exploration that can reveal insights about cognition.

Here we will examine the works of such writers as David Herman, Lisa Zunshine and David Porush, all of whom are drawing on the Cognitive Sciences and setting forth programs for the navigation and interaction between the two cultures. Others will be discussed, Zoltan Torey and Jan Slaby, working in the humanities, beyond literary studies, will also be discussed. The main concern of this chapter will be to detail what these writers see as the drives, goals, concerns and pitfalls of the field of Literature and Cognitive Science which establish a range of approaches, and to highlight particular concepts of interest and to select appropriate terms for use in the rest of the thesis. To simplify and give structure to this task, and provide contrast between approaches, I will further subdivide this discussion into questions and concerns, a necessity in order to navigate the diverse range the writers represent and to provide for comparison. 
PART TWO:

WHAT DOES COGNITIVE SCIENCE HAVE TO OFFER LITERATURE?

Beginning with approaches which affirm a close relation to scientific method and moving towards those using interpretive method will trace the range of discussion taking place around the question 'What does Cognitive Science have to offer Literature?' David Herman's focus on linguistics and his introduction to the collection of essays he edited, Narrative Theory and the Cognitive Sciences 5 provide an excellent place to start as he not only gives examples of how an interaction between Cognitive Science and Literature can take place but is also an example of someone involved in and conscious of prescribing a field of study. Acknowledging the shift in emphasis from 'Literature' as a whole to a subset in literature studies, 'Narrative Theory', should not diminish the fact that Herman is directly concerned with that relationship that we are concentrating on as a whole. Indeed, Herman is conscious of the collection as actively constructing a program for study that others should follow, and remarks that "the essays in the present volume can be construed as making a case for the inclusion of narrative theory on this roster [the roster of the cognitive sciences], at the very least as an autonomous module within linguistics and language" (p.4). His manifesto is one of inclusion, one which will result in "an inquiry into the common ground between theories of narrative and research in the cognitive sciences."

Undoubtedly, these comments point towards a desire for the bridging of the gap described in C.P. Snow's 'the Two Cultures, ${ }^{\prime}$ noted by Herman in his

5 Herman, David. Ed. Narrative Theory and the Cognitive Sciences. California : CSLI Publications, c2003.

6 Snow, C.P. “The Two Cultures." Leonardo, Vol. 23, No. 2/3, 1990, pp.pp.169-173. 
introduction, and the creation of an approach to Narrative Theory that takes sustenance from the authority that the Cognitive Sciences inspire as both of the cultures learn to talk to each other and further their understanding of the world. In this way Herman affirms narrative as the main faculty that humans use to understand the world and would posit the adoption of the knowledge created by Cognitive Science as the way to add validity to that affirmation. Characterizing two approaches he has marked, between the investigators of 'making sense of stories,' in which the paradigms and theories of Cognitive Science are used to show in detail how we process narrative, and 'stories as sense making,' in which narrative is the tool of cognition and can serve to enhance that faculty, Herman is arguing for "the advantages of construing stories as both a major target of and an important basis for cognition" (p.12). In particular, the ideas, methodology and results of a science should all be given weight as possible means to this end: the example of Artificial Intelligence is invoked as that area of study which has provided ample evidence of the ways in which knowledge produced by science may differ considerably from what we might expect to 'naturally' be the case in our everyday interactions with narrative; that the attempt at creating artificial narrative constructs for another agent is much less straightforward than our own automatic processes would suggest; and that end is a place where the various different 'streams of influences' from the humanities can be brought together with those of the sciences in the pursuit of modelling the human mind. This positions Cognitive Science as the centre of Herman's approach and characterizes it as that which has significant understandings to offer, both as a new and potent generator of knowledge, to Narrative Theory and by extension makes a case for the usefulness of the Cognitive Sciences to Literary Studies as a whole. 
Herman has also spent time creating a way to understand how the brain and mind work. In his article "Storytelling and Sciences of the Mind"7 he provides an example of what the appropriation of the tenets of Cognitive Science can elucidate from a text when used as a basis in lieu of more traditional approaches; here however, he is primarily using linguistics. Using a face-to-face interaction between two women and an interviewer as his case study, Herman identifies a number of concepts informed by narratological and cognitive research:

(1) positioning; (2) embodiment; (3) the distributed versus localized nature of mind; (4)emotion discourse and "emotionology"; and (5) qualia, or the idea that conscious experiences have ineliminably subjective properties, a distinctive sense or feeling of what it is like for someone or something to experience them. ${ }^{8}$

Herman's notion's of 'embodiment' and 'the distributed versus localized nature of the mind' are of particular interest to us. Of embodiment he remarks that "the mind is always and inalienably embodied; minds should be viewed as the nexus of brain, body, and environment or world" (p.317) and "cognition should be viewed as a supra- or transindividual activity distributed across groups functioning in specific contexts, rather than as a wholly internal process unfolding within the minds of solitary, autonomous, and de-situated cognizers" (p.319) as he describes the distributed nature of the mind. Affirming the individualised mind of an agent to be a result of the feeling of embodiment within a larger cognitive construct that includes the environment and culture the agent is embodied within provides a description of the mind which is actively interacting with that which is around it as well as, by the

$7 \quad$ Herman, David. "Storytelling and the Sciences of Mind: Cognitive Narratology, Discursive Psychology, and Narratives in Face-to-Face Interaction." Narrative, Vol. 15, No. 3, 2007, pp. 306-334.

8 For a discussion that informed my decision not to use the contestable term 'qualia' for this thesis, see Dennett, Daniel C. "Quining Qualia." In: Marcel, A. \& Bisiach, E. (eds.) Consciousness in Modern Science. Oxford University Press, 1998. 
performing of utterances and actions, constructing that environment and culture. As a model of the mind Herman's description is one of a feedback loop where the individualised, embodied mind is part of a process that oscillates between affecting and being affected by the environment just as the environment is affected and affects the mind. This definition of the mind as distributed is important and helpful as it allows us to conceptualise the mind in a way that is not reliant on oppositions between definitions of material or mental realms: both material and mental are given the same status in a model that treats all as distributed elements of cognition, whether those elements be the process of thought experienced by an individual agent or the physical constituents or artefacts of the environment that agent is interacting with. This is important in any discussion of fiction and literature, as the interaction of agent with artefact begins to break down the boundaries perceived between the material and the mental.

In this way Herman is able to demonstrate an approach that sits between 'making sense of stories' and 'stories as sense making'. The result of this approach is a theory of the mind as distributed. To take the word 'distributed' as meaning 'not centralized' goes some way towards understanding Herman's model: the 'mind' is not merely restricted to the environs of the skull and is both constituted by and constitutes our surroundings. The main effect of this idea is to place emphasis on the inputs and outputs of the brain as, logically, what we put out into the world as action becomes part of the world that then influences, via the senses and the impressions generated by them, the physical nature of our brain. It also explains that interesting occurrence that is observed everywhere: we behave differently depending on whom we are around. Herman's insistence on the importance of this fact, that our minds are so influenced by our surroundings, leads him to claim that the mind is distributed and, even more boldly claim, that our minds are only accomplished via actions, specifically utterances. For Herman, the mind that we feel behind the eyes is a small chaotic part that is only truly given form when it is fixed by the action of speech, writing or other communication and sent out into the world. 
Lisa Zunshine too has been involved in her own endeavour of collection, recently producing a volume titled Introduction to Cognitive Cultural Studies. Although this collection contains a section entitled 'Cognitive Narratology' in which Herman's work is represented, Zunshine's naming of the field to include 'Cultural Studies' signifies yet another, similar but not congruent, approach to the concerns surrounding Literature and Cognitive Science. Indeed, Zunshine in her introduction makes explicit a connection between the approach represented in Raymond William's The Long Revolution ${ }^{9}$ as a foundational Cultural Studies text, and 'cognitive-evolutionary' approaches. This book, building upon and expanding the scope of her previous publications, is clear evidence of the emergent nature of the field.

Instead of Herman's emphasis on Narrative Theory, Zunshine's general thrust in her earlier book Why We Read Fiction ${ }^{10}$ is that which traces a need to take into account the advances in Cognitive Science, extrapolate and construct frameworks from these discoveries and apply them to our interpretations of understandings in Literature. Herman and Zunshine acknowledge each other at the beginnings of their works: obviously this need for the orientation of Cognitive Science relative to Literary Studies is a major concern for both of them. Herman's work is particularly concerned with finding a 'descriptive grammar' for narrative, and by extension the workings of the brain and the mind; Zunshine focuses on a theory she feels is enlightening to our understanding of the writing/reading process in regards to the human interaction between agent and text, rather than abstract elements resulting from Herman's linguistically centred approach, which results in Zunshine's model being one that can be used as a framework that augments the interpretive approach towards literature. It is interesting to see here that the different direction that these

9 Williams, Raymond. The Long Revolution. Great Britain: Broadview Press Ltd, 1985.

10 Zunshine, Lisa. Why We Read Fiction: Theory of Mind and the Novel. Columbus : Ohio State University Press, 2006. 
two writers have taken the same concern can result in some very different relationships to a text, in particular in terms of emphasis: the sense of mind as a distributed energy created and reacting to the environment and agents around it that Herman's account engenders is not to be found in Zunshine's.

At the base of Zunshine's arguments and observations is a model of understanding she calls Theory of Mind. Theory of Mind is the premise that to understand another's behaviour we must attribute thoughts, feelings, desires and other mental phenomena to that agent. Adopted by Zunshine from Cognitive Psychology, this is a theory born from the observations by neuroscience of a part of the brain in which certain cells, called 'mirror neurons', react in similar ways when we perform an action, see someone perform an action, or even read or hear of an action being performed. This is underpinned by the consideration that this faculty has evolved from the need to understand not just the actions of other agents but also the thoughts and emotions of the agent performing those actions, a faculty that directly links an agent's actions in the world with our own experience: when thinking and performing an action, the mirror neurons fire, and create a link between that thought and action; to observe another perform that same action, the observer's mirror neurons fire in exactly the same way and activate the same link between thought and action, allowing us to postulate that the action of another must have been caused by the same or similar thought process. This ability to attribute and understand another's actions by relating observances to previously experienced thoughts and emotions is not without shortfalls, however. Using the television show "The Office" in her article "Theory of Mind and Fictions of Embodied Transparency"11 Zunshine shows both how Theory of Mind can be shown to operate through modern media and why it is important that we keep in the frame of our studies evolutionary theory even when it may seem as though our understanding of modern culture would be ample to interpret this text. By first stating two

11 Zunshine, Lisa. "Theory of Mind and Fictions of Embodied Transparency." Narrative, Vol. 16, No. 1, 2008, pp. 65-92. 
assumptions she is working from, that "Theory of Mind is a 'hungry' adaptation that constantly needs to process thoughts, feelings, and intentions...[and] that the body occupies a double position in relation to this cognitive hunger, figuring as both the best and the worst source of information about the mind" (p.2) Zunshine explains how as the prolonged observation of the camera lingers an observer's Theory of Mind works overtime hungrily processing as much information as it can, creating awkward emotion for a viewer that is more intense than mere understandings of a breach of etiquette could create. This occurs precisely because, as shown in the quote above, our application of Theory of Mind is unstoppable and while Theory of Mind places the body and action as a privileged informational source, we are also aware of the possibility that we are misreading another's actions: with the continuous build up of information in these uncomfortable moments "The Office" delights in portraying, however, the possibility of misinterpreting these moments of social discomfort dissipates as our Theory of Mind continuously and uncomfortably recalls our own emotions in similar situations for as long as the camera lingers.

At the locale of the mirror neurons, there is no physical or functional difference between the performing of action and the observation of agents performing that action. Particular emphasis is given to the idea that the operation of this faculty, although able to be impaired, is unable to be stopped and for the most part operates at the subconscious level. The ability of this faculty to be impaired is important as this impairment has shown us that previous ideas of how we individually create meaning in a collectively dependable way, especially regards creation of meaning as we read, need to be re-examined. Specifically, scientific advances in the knowledge of autism and the discovery that an affliction of that kind can severely hamper an agents' ability to imagine a conscious state, real or represented through fiction, behind another's actions, throws doubt on the previously held belief that it is only our collective history as readers that allows us to dependably disseminate understanding of the kind intended from a text, whether that text is televised, face-to-face interaction or novel. 
This shift is important as it signals the need for informed students of Literature to move away from an understanding of our interactions as resulting from an ability to learn towards the acknowledgement of a faculty much more innate, biological as our senses, uncontrollable and insatiable as an evolutionary need. Neuroscience and the Theory of Evolution act as the scientific grounding for Zunshine's Theory of Mind, creating a persuasive model of how agents understand and interact with each other in both real and fictional worlds. 


\section{INTERLUDE:}

\section{THE BRAIN-MIND}

In the above discussion we start to see the first great area of contention that will run through the entirety of this thesis: what is the mind? Taking Cognitive Science to include any knowledge that is produced from scientific investigation of the brain , and Literature, especially the novels we are to be analysing, as artefacts of mind, then we have a problem if what 'mind' means to any set of writers is fundamentally different to another set. I take Herman's suggestion of staying away from the extremes of behaviourism, that set of ideas that holds that thought and feelings can be explained through scientific understandings of the brain without reliance on or reference to the mind which it regards as a hypothetical construct, and cognitive or idealist notions that, in the extreme, suggest that everything, including the matter that composes the brain, is composed of ideas. These positions are based on the idea that everything that is not matter must be mental, a view that can be traced in western thought back to antiquity, which is commonly thought of as dualism. Although interesting, there is not the space nor is this the space to trace even quickly the development of this idea, save to acknowledge the problems that adhering to terms with their basis in behaviourist or idealist systems poses for this thesis, and to propose a solution: the brain-mind. This term is to be used in all cases of discussing non-physical events to signal that what is traditionally thought of as mental has such a strong connection with the material function of the brain that it must be considered the same process in order to engage in discussion of the interaction between Literature and Cognitive Science. Continuing to divide the field of enquiry between objective, empirical descriptions of the brain and humanistic conception of the mind complicates any attempt at identification and discussion of the common ground between not just ideas of brain and mind but also between the Two Cultures. 
PART TWO:

CONTINUED

A writer continually concerned with the need to clarify terms in this discussion is David Porush. His reply to the question, 'what can the Cognitive Sciences offer...' is a complex one, one born from, according to Porush, science's discovery and suppression of an "intolerable intrusion of the irrational" ("Eudoxia", p.41) ${ }^{12}$. What creates difficulty in Porush's view is science's difficulty at coping with concepts such as the Heisenberg Uncertainty principal, where the understanding of the position of an electron was shown to be untenable, and Gödel's proof of the impossibility of a complete description of the universe. The understandings put forth by Heisenberg and Gödel are not illogical, and yet do not fit within the rationalising framework of modern science where everything can be shown to be part of the 'clockwork universe.' Although these discoveries that affirm the effects of subjective observation and the formally chaotic complexity of the natural world have been acknowledged by scientific endeavours such as quantum mechanics, for Porush this 'intrusion of the irrational' both allows Literature a place within the scientific understanding of the world and affirms the need to include the irrational, as opposed to science's emphasis only on the rational, in any enquiry which strives to describe the world, particularly the brain-mind.

What Porush means by 'the irrational' comes from some clever re-arranging of binaries. Porush begins his definition of 'irrational' by first examining the history of rational numbers that, although seeking idealised notions were still tied to notions of the discrete. The history is concerned with Pythagoras, and the definition of

12 Porush, David. "Voyage to Eudoxia: The Emergence of a Post-Rational Epistemology in Literature and Science.” SubStance, Vol. 22, No. 2/3, Issue 71/72: Special Issue: Epistémocritique (1993), pp. 38-49 
'rational' is that which was related to "objects that could be held and owned" ("Hacking" p.542). ${ }^{13}$ The irrational, therefore, is what cannot be related to objects that can be held, such as the numbers that fall between the rational numbers, the abstract that does not reference the real. However, through a reading of Beckett's novel Murphy Porush suggests that the irrational can also be used to refer to that which does exist but cannot be explained, in Murphy's case his own synaptic activity, just as we use the term to refer to those numbers that can be proven to exist but cannot refer. Finally, however, Porush prefers Gaston Bachelard's argument, that the nature of the real and reality is irrational rather than rational, and accepts the notion that "the great opposition is between rationality and reality, with rationality finding its best expression as science" (p.548), positioning Literature as that which can reconcile and also show the opposition. This fits with Porush's characterisation of the human brain as a "vast irrational machine" (p.543), an irrational machine that must be interfaced with if cybernetics can become possible. To associate the real with irrational, placing all rational constructs as opposing rationality, asks for an examination into the relationship between science and reality and by extension literature and reality. To associate the real with the irrational, placing all rational constructs in opposition to reality, asks for an examination of the different relationships between science and reality, and literature and reality. Positioning Literature as that which can incorporate the irrational into its construction of knowledge also allows Literature the status of being more fully mimetic: through Literature's ability to incorporate irrationality it can therefore encompass the real, in contrast to Science which through its rationalising methodology must necessarily be an abstraction from the real. Literature is able to present (by being an object incorporating irrationality), as well as represent (by examining, modelling and describing), the irrationality which is reality, whereas the purpose of Science is to eliminate that irrationality and create rational models of understanding. Literature is, in this sense, already that machine

13 Porush, David. "Hacking the Brainstem: Postmodern Metaphysics and Stephenson's SnowCrash." Configurations, Vol. 2, No. 3, 1994, pp. 537-571. 
that interfaces with theirrational human mind in the way that cybernetics and cyberspace have yet to achieve.

Literature is able to present, by being an object of irrationality, as well as represent, by examining, modelling and describing, the irrationality which is reality, whereas the pursuit of Science is to eliminate that irrationality and create rational models of understanding. Literature is, in this sense, already that machine that interfaces with the irrational human mind in the way that cybernetics and cyberspace has yet to achieve. The sciences produce a rational discourse, creating knowledge from the unknown chaos around, potent knowledge that, if unexamined, Porush fears may actually hide 'the truth of the matter' as notions of irrationality are further and further sidelined, the abstractions from reality that science produces one day begetting a rationality that has little or nothing to do with reality. Porush characterizes his work as a struggle that takes place between the epistemological activities of science and literature, those activities that generate truth. By discussing where Literature fits in this epistemological contest, particularly regarding the concepts of brain and mind, Porush is inviting us to start re-evaluating where on the spectrum between rationality and reality we might place these concepts and activities, or whether it is necessary to amend or even reject a model that positions reality and rationality, and therefore literature and science, as opposites. Although as Porush is not arguing for a 'common ground' as Zunshine and Herman are he is quite contentiously examining one of the core aspects of this thesis, the relationship between Literature and Cognitive Science.

Porush is not, however, against the advances that these new sciences promise: many of his articles and writings look wistfully forward to where cyberspace, as it is popularly understood and visualized by films like The Matrix, becomes a reality. Porush does not believe that Cognitive Science is an unnecessary or dangerous enterprise in itself, for to survive we need rational as well as irrational understanding, but that the current privileging of Cognitive Science as a way of knowing over other forms must be examined. This becomes apparent when he 21| P a g e 
discusses Cognitive Sciences, which he includes as a subset of cyberspace and cybernetics, and the power of these approaches' rational understanding on the world and the possible effects of the unqualified acceptance of that understanding:

[i]n some senses, it is irrelevant whether cyberspace is technically feasible or not. What has been significant about it is its mythological power and what it reflects back to us about our cultural concerns.

(“Eudoxia” p.39)

If cyberspace is in part perhaps technically impossible, Porush believes it still to have power in a mythological sense, and his concern is that by borrowing the potency behind the idea of a scientific rationality this mythological power may become unquestionable. Using myth to generate knowledge about the world has long been acknowledged as an ancient and powerful tool of understanding, and remembering to treat scientific knowledge as at least having an influence similar to that which myth holds acknowledges that scientific knowledge is at least partially constructed and comprised of elements of our society and culture, in much the same way as we understand art, cultural practices and narrative fiction to be and also allows for the formal examination of scientific knowledge in a questioning tenor from outside the methods and discourse of science. The treating of discoveries and concepts of Cognitive Science, such as cyberspace, as having a mythological power also suggests that the examination of these rational understandings can take place in much the same way as the examination of Literature occurs.

The particular cultural concerns mentioned by Porush are those that change our understanding, usually through the vehicle of metaphor. The metaphor of the 'brain as a machine' or 'computer' is especially consuming in a framework, such as cybernetics, where it is postulated that all interaction can be explained through the movement of information. This ability of scientific, rational knowledge to affect the everyday irrational knowledge is evident in such cases when distinctions dissolve between the mind and computer, a move fuelled by the promises of cybernetics, as the brain can be thought of simply as an information processing and communicating organ: the effect of assuming the 'Brain as a Machine' metaphor to be literally 22| P a g e 
accurate has "successfully coloured the way we work, speak, think, plan and play as a culture at large" ("Cybernetic Fiction" p.374) ${ }^{14}$. The field of Literature and Cognitive Science for Porush is a field in which we examine the influences of these scientifically generated metaphors upon our understanding of the world, both as embodied individuals and in the collective entities we call society, culture and the brain-mind.

Part of Porush's work is specifically aimed at the examination of the metaphor of the brain as machine and his most interesting comments concern the way he envisions the brain-mind should be understood so that our interactions with text and world can be adequately modelled. Both his characterization of the brain as 'a metaphor machine' and his definition of transcendence as "the moment when we recognize that the cognitive is the metaphorical" ("Hacking" p.551) rely on the well worn machine metaphor to elucidate his conception of what a model for understanding the brain-mind should look like. These quotations point to the notion of representation being crucial in this process of understanding the brain-mind as a metaphor making machine, as the brain-mind operates through the process of one thing being represented as another thing. Looking at the etymology of the words, metaphor is created out of Greek forms meaning 'to carry' and 'change, substitution, permutation or transformation', and representation is the 'act of evoking the thought or idea of someone or something'15. Representation and metaphor are the means that the brain-mind uses to provide a link between the world perceived and our understanding of the world, a process which Porush argues must be thought of as irrational as it does not follow the procedures for the formal generation of a rational knowledge that science undertakes. The fact that neither representation nor metaphor is constrained in regards to what may be compared with what further

14 Porush, David. “Cybernetic Fiction and Postmodern Science." New Literary History, Vol. 20, No.2, 1989, pp. 373-396.

15 Etymology informed by the Oxford English Dictionary Online on 7th March, 2011.

$<$ http://english.oxforddictionaries.com.helicon.vuw.ac.nz/> 
characterises the processes of the brain-mind as irrational, as Porush uses the term. However, Porush's purpose in his work is to discover through the critical interpretation of literature the places of contention in the understanding of brainmind and its characterization as machine or computer, rather than working out a 'representational brain-mind' model himself. Porush's conception of an appropriate model of the brain-mind is one that affirms the power of metaphor and representation in the operation of the brain-mind.

Zoltan Torey in his book The Crucible of Consciousness ${ }^{16}$ has devoted himself to creating a model of the brain-mind, one that includes those processes that Porush has found needful in our understanding of the brain-mind. Much of The Crucible of Consciousness is concerned with tracing the evolutionary underpinnings that would make such a model possible, but his model, with which we are primarily concerned, is rich in scope and describes a fully functional brain-mind. Torey's work can be closely aligned with Porush's in that Torey's model of the oscillating attention process and the two-tiered neuronal model could very well be the model that Porush was envisioning in his work. Torey's model gives us the mechanism which allows for the creation of the metaphor in the way that Porush envisioned. Attention, or, more specifically, neuro-electric stimulation which is evidence of attention, rapidly highlights regions in the left and right hemispheres of the brain that, if the brain had not evolved asymmetrically, would be mirror images. As it is, the right hemisphere handles what Torey calls the primary percept, what might be called the neuronal recording of a visual, audio or somatosensory experience, the bundle of sensory impressions of an event. The left hemisphere is where the secondary percept is housed, the word. The attention on one necessarily throws attention on the other and together creates that kind of symbolic representation where one thing is another even though there is only an arbitrary reason, what Porush would refer to as an irrational reason, for that to be the case. This process of

16 Torey, Zoltan. The Crucible of Consciousness: an Integrated Theory of Mind and Brain. Cambridge, MA : MIT Press, 2009 
oscillating attention maps the process by which the consciousness is metaphorical that Porush affirms as stimulation is begun by the input from the irrational world and carried between the two hemispheres until it is transmuted into thought by being passed into the higher level of neuronal activity. Like watching an actor dance as they are reflected in a clear pool of water, the accord between the movement of image and actor may make it difficult to distinguish where the first move is being made, although the ripples on the pool of water make it easy to distinguish between the two, so too does it become difficult in Torey's model to state whether primary or secondary percept holds primacy. This is in fact one of the strengths of Torey's model, as the secondary can excite the primary as easily as vice versa, and both allow for continual thought as the attention oscillation swings back and forth but also gives an explanation for the human capacity of imagination: stimulus of the secondary percept in various ways can excite the primary percept to join and combine in ways that need not have been experienced before. The emphasis on the word in Torey's model as just as important, not a optional extra that came after sensory ability, shows the word and the primary percept to cleave so closely that from a functional point of view they are the same.

This part of the model describes what we would usually call the unconscious workings as, barring unfortunate accident, the stimulation of one half of the percept pair cannot fail to excite the other; our conscious agency of thought Torey ascribes to a second tier of neurons that are dedicated solely to observing the interactions of the base tier. It is this function of the brain-mind that Torey suggests gives us that feeling of being within and watching our own thoughts, the effect of being conscious of our conscious activity. This feeling of watching has caused problems for philosophers of mind as hard-line behaviourists resort to phenomenological occurrences arising from a determined system and those invoking ideological notions were at a loss to show where the 'core' of consciousness they felt to exist resided within the brain. Torey's model does not depend on a core for the consciousness, as the second tier is distributed throughout the brain, nor does it 
ignore the problem of primacy between thought, the product of a mind, and the physical action of the brain. By avoiding phrasing this as an either/or problem Torey is able to take the best from each system: the primary tier of neurons unstoppably connects percepts together as we receive new stimuli, but the higher tier can, but does not have to, take the observation of that activity and feed that back into the primary tier's function as a new percept, which necessarily generates the kind of percept joining as described above. This generates the feeling of watching our thoughts as, at a neuronal level, we actually are: those thoughts, however, are all created by an arbitrary pairing and are therefore representational in nature.

Torey's model, as focused as it is on the role of language, invites comparison with Herman's 'mind as distributed' model, although the former does not place so much emphasis on the importance of the performing of utterances to give the brainmind the shape we feel it to have. Herman's model describing the brain-mind as distributed through the environment and culture that affects and is affected by an agent contains the same process of 'carrying between' meaning that Torey's modelling of the oscillation of attention between two meaning creating percepts creates. Torey's model provides that 'wholly internal process' that Herman recognizes cannot be the entirety of the cognitive process and gives a model that describes the interaction of Torey's brain-mind with the world around. These two, therefore, give the most solid model of the brain-mind, one that is intimately connected with language and representation, and works well as the model that can underpin Porush, Herman and Zunshine's concerns around culture, society, literature, and what Cognitive Science can both offer to these concerns and take from the understandings of Literature. 
PART THREE:

WHAT DOES LITERATURE HAVE TO OFFER COGNITIVE SCIENCE?:

Although Porush, Herman and Zunshine are targeting an audience of academics situated in the Humanities and its various sub disciplines, there is the notion, implicit or explicit to varying degrees, that this work should generate ideas and outline concerns that Cognitive Science should take into account. Beginning with Porush, who is working closely with literary interpretation and who also has the hardest line for what Literature can offer Cognitive Science, we will now trace the spectrum of opinion on this matter. Porush sees Literature as undervalued and in need of greater emphasis as one of the most important ways in which we understand the world and ourselves. Over and over again he characterizes the meeting of the two cultures as a contest, which only now has Literature been given, partially through the inadequacy of Science to address and enfold irrational understandings which accept the chaotic and unknowable of nature without abstracting simplification, "the power to contest science's supremacy as an epistemological force, and on science's own terms" ( "Cybernetic Fiction and Postmodern Science" p.373).

These are bold claims, the effect of which is a shift in emphasis which places the rationalizing, abstracting methods of empirical science directly opposite the irrational, products and artefacts of the brain-mind, such as Literature and which are therefore necessary for the construction of a holistic world-view. Using this as his core claim, Porush goes on to demonstrate how when writers of novelistic fiction take cybernetic principles as their thematic concern those writers are able to demonstrate the inadequacy of the computing model for representing and understanding human cognition: 
The single unifying feature of cybernetic fictions is that they pose as cybernetic devices which ultimately-and this is the source of their power and postmodernism-do not work. In other words, they are soft (vulnerable and uncertain) machines (systems which strive for invulnerability and completeness). Their tacit twofold message is clear: the text-as-machine is both more and less than what it appears, it's an oxymoron. Furthermore, humans are not merely mechanisms, either, so that the communication between soft-machine human reader and softmachine text cannot be reduced to cybernetic calculations, for in cybernetic terms, both continually add noise to the channel of transmission.

The reductive account of communication between reader and text characteristic of the cybernetic model of the brain-mind is precisely what Porush shows to cause difficulties in his reading of Italio Calvino's short story "Night Driver."17 In Calvino's story a protagonist becomes immersed in a paradoxical situation in which the transmitting of a message results in the message's being unable to be received, as the protagonist reduces himself conceptually to a message transmitting device that creates an abundance of intolerable 'noise' to the transmission of, not just the protagonist's message to his estranged lover, but also between reader and text. Invoking the power of Literature as mimetic in nature he quite convincingly explains how writers of fiction can show that the scientific conception of the brain can be seriously flawed when applied to mind. Fiction occupies a special position in relation to science as fiction, which can combine both the rational and irrational through its ability to both present and represent, and reality, that which according to Porush is defined as irrational, are not opposites. Fiction is not the discourse of reason that Porush describes either: if the world of reality carries such qualifications as true, apprehendable, understandable, then we

17 Calvino, Italio. T Zero. New York: Collier Books, 1970.

$\mathbf{2 8 | P}$ a g e 
should not understand fictional worlds to simply be untrue, undetectable and incomprehensible, for we know that is not the case, yet it is what the placing of these terms into a binary would suggest. Neither fiction nor science can occupy the 'irrational' position that Porush gives to nature, but by dint of its ability to present the irrational, epitomised, Porush argues, by cybernetic fiction, fiction is therefore able to get closer to irrational everyday reality than the attempts of science that must adhere to formal reason. Truly, an entity of fiction, meaning both the characters and environments within fiction and the fictional text itself, is one that simply operates in ways not available to factual texts. Both fictional and factual entities share many of the same qualifications and what joins reality and fiction is language: fiction therefore is in an optimum position to explore the intricacies of how the brain-mind functions, not just act as evidence of those functions, as fiction can both show through its mimetic nature the operations of the brain-mind and examine those operations in ways not available to science. It is Porush's argument that the creation of knowledge from fiction and literature is entirely possible and valid, but is not yet considered that way from a Cognitive Science viewpoint; the aim of this thesis is to show how this exchange can be possible. The middle ground that Literature and fiction occupies on Porush's spectrum between rationality and irrationality will become of increasing importance through this thesis.

Porush's manifesto, therefore, is not to totally disregard the sciences and their models, but to urge the critics of literature to consider fiction as of at least as much importance in creating truth claims as the theories of science. The commingling of the two kinds of knowledge will not necessarily debase and muddy each other's claims, not if they are brought together with care. Porush holds hope for a future which:

Combines the epistemological potency of science's rational procedure with literature's irrational, epistemologically potent method for representing the mind, that most irrational of objects. ('Voyage to Eudoxia' p.48) 
Porush's dream for Literature and Cognitive Science is one in which the central questions of our voyage for knowledge are changed, so that they "will not be 'How do we know?' or 'How shall we be?' but 'How shall we transcend?' and 'How shall we exit the loop?'" Cognitive Science has answered the first two questions, and drawn up a claim as to why these answers are the only ones possible, and therefore the only ones worth giving; Porush's 'irrational method' which keeps literature and fiction as the soul and centre of the process actively pays attention to questions and knowledge excluded from modern science as it seeks to create a complete and abstracted mode of the world.

Neither Zunshine nor Herman characterize or would characterize the issue of the meeting between the two cultures of Cognitive Science and Literature as such a battle between Reason and Irrationality; both however do acknowledge the problems of the gap between the two approaches. Zunshine comments on 'fear' as being a barrier to any true cross-disciplinary practice, especially towards having to accept what could result. Her arguments are almost entirely based upon the need to use cognitive science as the factual basis for literary study so as to sustain the claim of being able to produce valid knowledge, and the reason these arguments are put so strongly is to combat that 'fear' that humanities scholars may feel as explorers into what is, for them, new territory. Due to the position Zunshine writes from, the fictional texts that she examines as examples will always obtain a place of privilege in her writing, as evidenced for example in her view that "it is a sign of strength in a cognitive approach [those approaches taken by cognitive scientists] when it turns out to be compatible with well-thought-through literary criticism" (Why we Read p.116] keeps those artefacts relegated to the position of evidence and verges on promoting the imbalance of Cognitive Science over literary ways of knowing that Porush identifies and argues against, although the emphasis on 'well-thoughtthrough' literary work suggest that Zunshine feels that some in the Cognitive Sciences may be tardily treading along the tracks already blazed in the Humanities. In Herman's work, however, while there is no indication of the need for the 
inclusion of something 'irrational,' that is, outside what Cognitive Science can integrate, into the study of Literature and Cognitive Science, he does put forward the concern that "[a]t issue is a strategy for sense making that contrasts with, but is in no way inferior to, 'scientific' modes of explanation that characterize phenomena as mere instances of general covering laws" (Narrative Theory, p.2). Sometimes it is confusing as Herman swings between the rubric of togetherness and establishing of common ground to the statement of goals that aim to make distinct the different approaches; ultimately Herman is recognizing the contest between these modes of truth construction and wishes to take what does not quite fit into either culture and create a space for it, although he is much more diplomatic in the positing of an integration between the two than Porush is, where one gets the feeling that the drive is generated by the need to reclaim land from a authoritarian aggressor. This notion of contrast, and the need to highlight that contrast, is where Porush and Herman would find the most to agree upon; where they would differ is where each discipline can draw the most influence, both in terms of the culture of Cognitive Science versus Literature, and the emphasis they place on linguistics on one hand and cybernetics on the other.

All the writers, Herman, Torey, Porush and Zunshine, have however emphasized the need for something outside the realm of Cognitive Science to extend and widen that discipline's knowledge of the brain-mind: for Herman and Zunshine it is the status of cultural artefacts as evidence, whether this be the linguistic study of face-to-face interaction or the effectiveness of television drama, that both affirms and is complemented by the findings of Cognitive Science; for Torey and Porush it is the importance of language and the need to include the notion of representation within the scope of both disciplines' endeavours. Also, through the contrasting of these writers' models for understanding the brain-mind we have come across concerns that run deeply within all: problems that stem from the conceptual separation of the material and the mental and other binaries, the need to keep in our frame of reference the power of social and cultural constructions, especially 
novelistc fiction and what its role in this debate may be. Through their texts these writers have created manifestos for the creation of an approach for others in literary studies to follow into the field of Literature and Cognitive Science, in part differentiated by their different disciplinary histories. But underpinning the process of producing formal knowledge in the Humanities is critique. The relation between the critical method and the scientific method will be the focus of the next part of this chapter. 
PART FOUR:

WHAT FURTHER? CRITIQUE AS MIDDLE GROUND:

...some of us should venture to embark on a synthesis of facts and theories albeit with second-hand and incomplete knowledge of some of them and at the risk of making fools of ourselves.

(Schrödinger, What is Life?) ${ }^{18}$

The above writers have all embarked upon this work of synthesis with the knowledge that they might be misinformed, or shunned by those they would most like to reach. Zunshine is especially admirable for admitting that "every single one of my speculations resulting from applying research in cognitive psychology to our appetite for fiction could be wrong"; and yet, this admission in the process of examining the interactions between Literature and Cognitive Science which is absolutely necessary. While the quote from Schrödinger does not illustrate the contestability of what is to be considered fact and what theory that the writers are all concerned with in one way or another, it does show that the need for synthesis to bring a new field of enquiry into existence is just as relevant today as it was sixty years ago, that across the gap between the cultures that C.P Snow described we still have problems speaking.

What this synthesis should be concerned with we have already outlined: the above writers have all given descriptions of the brain-mind that are variously concerned with notions of society, culture and environment, language and representation, descriptions which they argue can provide profitable additional

18 Schrödinger, Erwin. What is Life?: the physical aspect of the living cell. New York: Cambridge University Press, 1944. 
dimensions to the work of Cognitive Science. How this synthesis is to be achieved, however, is still being worked out, as Zunshine's most recent book demonstrates. Even though the writers above have given advice, mostly in the form of example, as to how we should proceed, some approaches are so different as to be incompatible. Of particular difficulty is that the notions of 'fact', 'theory' or even perhaps 'hypothesis' as conceived by Cognitive Science are not compatible with methods for knowledge demonstrated by the above writers. The way forward lies in the question of what Literature can offer Cognitive Science, so as to make the claim that sufficient and important knowledge can be created by analysing literature, not simply to show the power of Literature, but to enrich this common project that seeks to understand the brain-mind.

For an answer I will turn to Jan Slaby, whose paper "Towards a Critical Neuroscience" is written from within the Humanities from a point much closer to the cognitive sciences than is typical of Literary Studies. Outlined within the article is an argument for a more self-reflective methodology within this new and powerful branch of science. It is not an attack on neuroscience; he affirms the descriptive power of neuroscience as a tool of investigation, but also makes a strong case for critique as a method of inquiry. Criticism is necessary: Slaby characterizes the neurosciences as having a 'seductive allure', a fantastic phrase that well communicates the power of scientific research to shape the imagination, define modes of thinking, and rank methodologies of enquiry. Perhaps this allure and its effects is a result of an eagerness to finally explore the grey continent, a desire to overcome the 'fear' of the unknown and accept the consequences that knowledge might bring. Slaby gives some examples of just how readily some, namely patients who have had their brains scanned, and corporate entities, are willing to accept neuroscience's descriptions as their new reality. That reality affirms the notion of a person and their characteristics being bound within an MRI, a reality that allows for the profiling of employees' 'emotional revenue' to be credited with scientific certainty. Not just transparency and active self-reflection upon practices by those 
working in the field is needed, Slaby argues, but also active critique by others from outside the field of neuroscience, outside science, even from without the academic community, 'the public at large', critique that goes as far as to discuss possible uses and the direction of this branch of study.

Identifying similar concerns to the writers mentioned above from his philosophy of science viewpoint, Slaby's point is that neuroscience, as part of Cognitive Science, needs knowledge from sources and modes of enquiry other than the sciences that allows integration of more than the 'facts alone', something that can identify the social contexts that the neuroscientific enquiry is situated within and draw links between those contexts and the advances of neuroscience in a meaningful fashion. For Slaby, that mode of enquiry is critique, a method fundamental to the humanities. Although detailed as a series of steps, Slaby's program of critique will be more useful to us as an ongoing process that is allowed to reference multiple steps at once as we read through the novels and the model they produce, taking from Slaby's suggestions in a way that is appropriate to the issues this thesis is concerned with and the fictional materials investigated. Not only are the steps necessarily connected, but also since these novels are performing critique as well as being the subject of critique the process needs to be flexible. The salient features of Slaby's program are as follows: an emphasis on examining the theme of inquiry in the 'richness of its contexts', societal and cultural amongst others, broadening the scope of the enquiry to further determine the boundaries of concerns arising from application of neuroscientific advances; stakeholders, those with agency within the process of creating knowledge must be identified and particular consideration given to how they affect the process and how they are created as stakeholders and agents; and, finally, what are the goals, concerns and 'normative standards' which society wants to guide the endeavour of science. Literature, in both its study and its generation, has a long and rich history of critique and particularly of the generation of value frameworks to use of the examination of that which interests it, that which is important to us: this focus of Literature on what 
matters to humans as opposed to Science's emphasis on what constitutes the world is the main distinction between the two cultures as has been explained to us by Porush, Herman and Zunshine, and therefore must be the basis for the synthesis of fact and theory between the two cultures. The writers above have given the connections and strands that Slaby asks be included in creating a critique, which will be used to synthesise the issues discovered above with concerns that arise though the reading of the novels.

Utilizing the arguments and perspectives of the critics discussed above in the process of reading the novels will not only investigate how they create models to understand the brain-mind, how they represent the interaction between Literature and Cognitive Science and give further evidence to support or refute theories posited by the critics, but will also demonstrate that they are fully functional critical resources, that resource outside Cognitive Science that integrates more than the 'facts alone' and creates a investigation into the emerging middle ground between Literature and Cognitive Science. The remainder of this thesis will be the elucidating of the results that applying this framework to the novels makes possible, and discussing how the novels too can then be said to be included as members of this endeavour, the field of enquiry, Literature and Cognitive Science. 
CHAPTER 2:

PRELUDE

Analysis of the novels Hard Boiled Wonderland and the End of the World by Japanese author Haruki Murakami and Tea From an Empty Cup by Pat Cadigan in this chapter will examine much of what the critics in the previous chapter have been concerned with. These two novels in particular and any novel in potentia are taking ideas of cognition and the mind available at the time of composition and working towards the generation of knowledge. The novels alone cannot be considered to be producing formal knowledge, yet one of the fundamental claims of this thesis is that literature can and has to be included as one of the various sources that we can draw evidence from to create formal understanding concerning the brain-mind as they are themselves products of that entity and therefore must contain evidence of the brain-mind's operations and abilities. Extracting this evidence will occur through the process of literary criticism and interpretation, as the narrative content of the novels is translated conceptually into knowledge. These novels are suited for this task as they are themselves concerned with modelling the brain-mind and the problems that arise from such a process, and the first part of this chapter will be devoted to creating a model from the examination of the two texts in relation to each other regarding this. As both novels' narratives move between different fictional worlds, this model will map and define the way in which the brain-mind reacts in these different spaces, a word used so as not to limit what the brain-mind can be said to react to as it can be used both in relation to physical spaces and conceptual spaces, such as those found in novels. Definitions which are generated by examining fictional realms will not reduced in value because they are derived from fiction, nor will they be only relevant when discussing fiction. Arising from this task of modelling the brain-mind will be issues surrounding concepts of embodiment, the interaction of spaces, the process which those spaces use to achieve that interaction, 37|P a g e 
and direct examination of how the brain-mind affects and is affected by the culture and society it is perceived to be situated within. These issues are by no means separate and will intermingle in ways which add depth to the model, resulting in a model which will then be evaluated alongside the models already given by the critical writings. This chapter will therefore be foregrounding the process of critique that this thesis affirms is also needed for the full development of the field of Literature and Cognitive Science. In this way literature is taken to be a primary source of information which ultimately enriches the multidisciplinary project which is enlarging our knowledge of the brain-mind. 
PART ONE:

MODELLING THE BRAIN-MIND

There is an immediate structural similarity between Cadigan's Tea from an Empty Cup and Murakami's Hard Boiled Wonderland and the End of the World: both exhibit an alternating chapter sequence, each sequence dealing with a distinct narrative. In Tea the first narrative deals with Konstantin, a homicide detective working on a case of 'gamers' stigmata', in which the participant in an Artificial Reality (AR) module has somehow managed to die 'out here' in the novel's everyday reality, a supposed impossibility. Konstatin's investigation takes her beyond the threshold of the reality of this futuristic novel and into the AR of "post-apocalyptic Noo Yawk Sitty." Yuki, the protagonist of the second narrative, is a young woman who while searching in AR for her missing mostly-a-friend, Tom, falls into the hands of a shadowy cabal run by the enigmatic Joy Flower, who seeks to manipulate Yuki into finding the door into 'Old Japan', another reality altogether. The chapters alternate between the two women's narratives, the pattern only broken by the chapters that begin and end the book. The text is filled with puns and improbable situations, interweaving between the narratives and clues which at first glance make no sense, all befitting a novel which mostly takes place in the AR world where the core claim is the half-truth, 'anything is possible.'

The nature of the dual narrative in Haruki Murakami's Hard Boiled Wonderland and the End of the World is anticipated by the title. The unnamed protagonist of the first narrative, an info-security operant for 'the System', inhabits the Hard Boiled Wonderland (HBW), an aptly named contemporary world presented to us through the wry observances of the protagonist as he attempts to understand the events which unfold around him when he finds himself to be the key piece in a battle between his own company and its darker rival, 'The Factory.' The 
prize in this battle is the protagonist's brain. The world of the second narrative, that of the End of the World (EotW), is a calm and tranquil counterpoint to the world of HBW where golden beasts with a single horn protruding from their forehead graze surrounded by an impassable wall. The protagonist of the EotW narrative, also unnamed, is engaged in a process of exploring his surroundings, the Town and its encircling Wall, in an attempt to be reunited with his Shadow and retain his mind. He is also employed as the town's Dreamreader, a strange profession in which he reads scraps of sensation from the skulls of the dead beasts ${ }^{19}$.

Unlike Tea, in Murakami's novel the characters do not step between the worlds and, bar one or two notable instances, the events of one narrative have no bearing on the events of the other. But the question of how the Hard Boiled Wonderland relates to the End of the World is one that is also relevant to the worlds of Tea. What precisely are the points of difference and convergence between these worlds? Examining the portrayals of the characters within the different worlds will yield a model of the brain-mind, a model centred on understanding the relationship between these worlds and their relevance to each other.

To begin constructing a model for understanding the relationships between the worlds represented in each novel I will take the terminology introduced in the opening chapter of Cadigan's novel, in which two men only differentiated by their ethnicity and culture are engaged in a trade:

“... I'm saying you're too out here to have stuff any other way."

The white guy rolled his eyes. "Oh, and I suppose your body isn't out here."

19 To avoid confusion, I shall refer to the protagonist of HBW as Watashi, and that of the EotW chapters as Boku. In doing this I take my cue from Jay Ruben, notable translator and self confessed fan of much that Murakami has written, who notes in his book Haruki Murakami and the Music of the Words that in the original Japanese the protagonist referred to himself by the word "Watashi", the more formal personal pronoun in Japanese, whereas the protagonist of the second used the word "Boku", the informal construction. I am using the translation by Alfred Burnaum where "I" is used throughout, but it is helpful to my analysis to use the Japanese terms as clear differentiation between the two narrators is crucial.

40 | P a g e 
"No, it isn't," snapped the Japanese guy. "That's the trouble with you people. Your body's not really out here. Your body's in here." He leaned forward over the table and tapped his head.

(Tea, p.17)

And again, when Yuki has her first encounter with another, Nick the Schick, in AR:

"Smell?" Yuki tilted her head, skeptical. "You can smell in here?"

"You pay extra, but it's always worth it. But I don't pay extra to be around someone who keeps saying shit like 'in here' or 'out there'. I don't come here to get my illusion ruined."

These terms, 'in here', 'out here', 'out there' and, suggested by the space left by the first three terms, 'in there', are difficult to pin point. In the second exchange, it is shown that they are relative terms, changing their meaning depending on where 'you' perceive yourself to be situated. If you are inside the AR world of Noo Yawk Sitty then 'in here' references the fact that your physical body is inside a special suit, called either a hotsuit or bodysuit by their users, which is programmed to take the electronic signals of the AR environment and represent them as physical sensations. Though your physical head is inside a helmet that screens the pictures of the artificial world just in front of your eyes, 'you' are outside the normal everyday reality of the novel to which 'out there' refers. In the first exchange 'out here' would be synonymous to the 'out there' of the second, but it takes on more of a meaning of a mind ordinarily embodied in an everyday reality than in the second exchange. In fact, Yuki's surprise at the ability of AR to create the illusion of the sense of smell is exactly what gets her a lecture; whereas in the first exchange the white guy is chided for being too taken in by the physical sensation of the world. 'In here' for the Japanese man is a state in which the position of the brain-mind is privileged over that of the body. What these two quotations are establishing is that it is not a fact of physicality that defines where 'you' consider yourself to be, but a case of where 
embodiment is perceived to take place. In certain circumstances whether you feel yourself to be 'out here' or 'in here' is a matter of choice. Where you feel yourself to be is the reality that matters; where a body is and is perceived to be becomes central to understanding and defining a space. For a seasoned collaborator within AR like Nick, 'out there', although not 'illusory', is not the world of consequence, because the perceived body, in this case an avatar created to negotiate AR which may or may not have any similarity to the user's actual body, is more important than the normal everyday body. These four terms come to trace a series of relationships based initially on the notion of embodiment that will define both the crucial similarities and differences between the different spaces and therefore what the novels portray as the relationship of brain-mind to these worlds.

The definition of 'out here' includes the spaces that we find Yuki and Konstantin inhabiting at the beginning of Tea. Even though the world represented is a futuristic one in which Japan has ceased to be a landmass, where the newest fad is facial hair for women and new technology is used to transport paying punters to a fully immersive artificial reality, we classify it as 'out here' because, like the world we inhabit, it is a space in which the brain-mind exists only as a collaborative structure, influenced and constituted by society and culture. Watashi in Murakami's novel also inhabits an "out here", the novel's version of normal everyday reality, a world much more contemporary to ours in terms of representation and only really distinguished as being possibly futuristic by the 'shuffling' technology that has been implanted in Watashi's head. But it is necessary to first map out classifications of the worlds of Tea in order to compare them with the worlds of Hard Boiled Wonderland.

'In here' is already partially defined for us by the quotations above. The moment a brain-mind becomes an instantiation of individualisation it is 'in here'. As these novels employ a first-person narrative, we as readers ride along in these characters much in the same way that Konstantin and Yuki ride along in an avatar: while in AR the experience of occupying an avatar is also 'in here'. How do we then define the space of AR? It is obviously a quantitatively and qualitatively different 42|P a g e 
space from the 'out here' that the characters first inhabit, although it follows the same definition of a space in which the brain-mind exists as a collaborative structure: in fact, the premise that AR and the Sitty rest on is one of collaboration begetting structure, where examples of interaction on multimedia screens (p.146), specialised construction of cyborg cliques (p.176) and strange sick games created by possible children (p.194) proliferate. Strictly speaking, the Artificial Reality of PostApocalyptic Noo Yawk Sitty is an elaborate construct designed to give the user of that technology the complete sensory impression that they are within another real space. Advanced technology stimulates the nerves of the body and takes information from the muscles, allowing the wearer of a hotsuit to feel the soil beneath their soles and the brush of wind over arm hair as they walk over plains, even while to an 'out here' observer all that would be seen is a suited figure lying on a bench, possibly strapped down. But to the participants of AR, the quality of the audio transmitted, in clarity of the screens that they view inside their helmet, the stimulation of the physical senses and, if you pay enough, the smells, must be immersive in a way we can perhaps only imagine in a lucid state of dreaming, a state of reality with extra qualifiers, hyper-reality.

To those 'out here' AR is called 'in there' as one would indicate that someone is in another room, an idea given emphasis as we consider that none of the above scenarios from the novel are unimaginable 'out here', and are images created seemingly from the flotsam and jetsam of the novel's 'real world' culture, just as novels are reflections and creations of our own. Therefore, AR is a fictional realm, immersive and containing a powerful culture to such a degree that it is only the acceptance by the participants of AR's artificial status that prevents it from being another 'out here.' It would be difficult to argue that the way in which users of AR create the culture of 'the Sitty' is any different than the way culture is created 'out here', save the degree to which those constructs are perceived to be malleable. Tom's comment, "Oh, what's that supposed to mean anyway, artificial reality"?... If it's reality, how can it possibly be artificial?" (p.28) shows how close these two worlds 
can be thought to be, yet the mere voicing of such a consideration highlights the importance of attributing the qualifier of artificiality to a distinct kind of space explains why participants of AR feel inclined to refer to that realm as 'in here', not just as a distinction between different rooms, but because the knowledge of the constructed nature of that world is heightened to such a degree that they feel embodied within it in the same way that they feel embodied within the avatars they adopt, or within their own physicality. The level of control that a participant within the AR space of the Sitty perceives themselves to have over their environment is comparable to the level of control we perceive ourselves to have over our own physical bodies.

There is a third world in Cadigan's Tea which has only had passing mention so far, that of 'Old Japan.' This world is mythical even in the fantastical construct called the Sitty, and the most unsubstantiated rumours in a world that proclaims itself as built on half-truths are those rumours in which it is possible to find the 'out door', out of regular AR and into 'something different'. Myth plays an important part in Tea as an instantiation of culture. In the opening chapter which is a key indicator for many of the tensions that are going to run through the narrative as a whole, the Japanese character is selling the experience of a myth, a rebirth myth, in which the world is saved from darkness by the ritual of dance, a tale of disagreement between Amaterasu and Susanoo. Myths, and dance, are cultural constructions, representations of a kind of knowledge that, although not formal, are held forth by a population and have power over the way individuals think and behave. It is no accident that the climax of Tea includes a ritualistic dance that concludes in events comparable to that of the myth that is being sold in the first chapter, and that the final chapter strongly suggests that Yuki has made her way into the mythical 'Old Japan', a world created by the ghost in the machine, a machine in part created with donated brains which, it is suggested, still carry the traces of the mind of a culture. To use terms like 'the ghost in the machine' as the novel does suggests the existence of a conscious entity with a physicality that is very difficult to locate, if it exists at all: 
coupled with the emphasis on myth, a concept which belongs to individuals only as they are participating parts of a whole, the characteristics of 'Old Japan' can be said to be distributed, disembodied, yet immediately recognisable, a discrete sphere. However, as Yuki demonstrates by her actions in the final chapter, an agent immersed in a space that shares the attributes of Old Japan is unaware of the distributed and disembodied qualities of that space: Yuki feels embodied within Old Tokyo, in this case embodied with a male physique, both feelings of embodiment that Yuki has no reason to doubt for some time. For these reasons I classify realms like Old Japan as 'out there', that are only discernible from 'out here' by those with privileged knowledge, such as readers possess, in this case the knowledge that Yuki is not a young man as she is told and believes in that final chapter. To be wholly 'out there' is to no longer have a body, to be part of the multi-consciousnessed entity of culture, society; but to those immersed in such a space, as Yuki is immersed in old Japan at the end of Tea, that space is as much 'out here' as the space that we were introduced to at the start of the novel. In these situations, without knowledge as to where the physical, normal everyday body is, defining what space is 'out here' or 'out there' becomes a difficult task.

By placing these different states into this model that focuses on embodiment as a key attribute we are able to elucidate some of the more pressing concerns that lie at the core of Tea from an Empty Cup. Importantly, a characters' sense of embodiment is always shown to be related to the sense that the agent has about their space, whether that space be distributed or contained, embodied or disembodied, recognisable or strange, immediately distinguishable from other spaces or part of a continuum. These distinctions can also be identified on a continuum, as one space may feel more discrete than another, yet not entirely distributed. The advent of technology that allows us to interact with machines in ways that have not been possible, that Cognitive Science and Artificial Intelligence are investigating, has become part of our cultural lexicon and invites thought on how we are to deal with and define the new conceptual and representational spaces 
that become possible as a result. By focussing on embodiment as a key factor in how we define the spaces we inhabit and interact with, whether everyday, artificial or fictional, an important process of the human brain-mind has been made clear. Where a body is and is perceived to be defines a space and influences the way in which we think about and behave within that space. Acknowledging this has created a model that traces the reactions of the brain-mind to the process of changing spaces.

The worlds of Murakami's novel Hard Boiled Wonderland and the End of the World are simpler to categorize. There are only two worlds in the novel and the amount of direct narrative crossover between them is more limited than in Tea. In the course of this section, however, comparisons will also be made between the realms of Murakami's novel and the ones already introduced in Tea to further highlight concerns and flesh out the questions that these novels are asking us to consider.

The Hard Boiled Wonderland chapters are, as we have already noted, in the order of 'out here.' Not much distinguishes the world which Watashi inhabits from that that we inhabit: even for non-Japanese readers there is perhaps surprisingly little that is alien in terms of culture. That which is alien, cabinets that lead to large caves under the bustling metropolis, buildings with illogically numbered doors, the threat of monsters that inhabit the dark and eat subway workers, is alien to the protagonist also, and therefore brings him closer to us as we register the bizarre nature of these events. Watashi's rather stoic attitude and repeated concern with the banal when faced with the strangeness thrust upon him again and again serves to anchor this representation as one that draws empathy from a reader rather than alienating them in a strange world. This stoicism has been remarked on by others ${ }^{20}$

20 Strecher, Matthew C. "Magical Realism and the Search for Identity in the Fiction of Murakami Haruki." Journal of Japanese Studies. Vol. 25, No. 2, 1999, pp. 263-298, is particularly concerned with how Murakami is able to use "magic realism" to bridge the gap between individual and collective consciousness and therefore expose what he sees to be a "steady decline of individual identity," whereas Dill, Jonathan. Murakami Haruki and the Search for Self Therapy. University of Canterbury, 46 | P a g e 
as symptomatic of a decline in individual identity of post-WWII Japanese which is noted to be portrayed in Murakami's work as comfortably similar to our own and a reason for his popularity in western culture. This decline of individual identity is evidenced further by the lack of individual names in Hard-Boiled Wonderland, which is also often a feature of Murakami's work as a whole. This imparts upon Watashi the importance of an 'Everyman' character, a symbolic embodiment of a whole and one whom it is intended may be substituted for other individuals, especially as Watashi's world contains so little to differentiate it from our own: what makes Watashi interesting is the tension between his being deficient in personality traits because of societal influences and the lack of personality that becomes his most distinctive attribute. This tension is a symptom of the contest between assertion of individual autonomy and the pressures of conformity that all feel if one is to be a participant of a society or a culture. Understanding Watashi to be an embodiment of modern life and culture is crucial to understanding Murakami's conception of the brain-mind and the way that Murakami portrays the interaction between an individual and their environment.

The world that Boku inhabits, however, is a much different one. The End of the World narrative begins with Boku's entering the Town, whereupon he must be separated from his Shadow, which will soon die without him and, upon accepting the post of Dreamreader, have his pupils scarred. Both undertakings are performed with a knife. The Town this narrative occurs within is small, contains a no longer

2008. < http://hdl.handle.net/10092/1004 > works through in his thesis the first eleven of Murakami's novels tracing a need for 'self-therapy' as the characters of the novels struggle with the cultural decline of post WWII Japan. Dil's pointing to Jung and Lacan especially informed my discussion surrounding Watashi as an Everyman figure, as that approach is essentially treating the characters as archetypes in the Jungian and Lacanian tradition. The label of Everyman, however, while allowing access to the notion of archetype through reference to the morality play signals the need of this thesis to not become overly encumbered by psycho-analytic influences in order to focus more selectively on the influences of Cognitive Science.

47|P a g e 
working clocktower, old buildings and a large forest, and is completely surrounded by a large wall that only the birds can cross. It becomes apparent that the inhabitants of the Town are only allowed to exist there due to their surrendering of their minds, a process that is linked with the surrendering of the shadow because, when the shadow dies, the mind is completely lost. The mind in this place is not perhaps what we would think of when usually invoking the word, as the inhabitants are not shambling zombies, philosophical or otherwise. Certain traits, however, deep emotions such as anger, sorrow or love have been lost to the citizens of the Town, to be replaced with a contentment which is not severe, modulated only by custom and acquired practice. The map at the beginning of the edition we are examining also corresponds nicely to a horizontal MRI scan of the brain taken just above the level of eyes: this is obviously a representation of a world in which matters and concerns relating to the brain-mind are brought into the fore, and the above examples signal clearly to a reader that this is a world of a different order to that of HBW where shadows are not subject to the cutting edges of knives: even if monster-infested subterranean caverns lie under Tokyo the events in HBW still adhere to recognisable physics. But for Boku, however, this is an 'out here' realm: no understanding of there being another world which might be a 'real' one is imparted to us by Boku's narrative, and at the beginning of the novel we are given no reason to suspect that this place, even though it contains unicorns and a sense of timelessness, shadows that can be separated from the body and conversed with, is any less real a relationship for Boku to his surroundings than our relationship to our own is to us. This is a reality for Boku, and although the customs of the Town may be strange to him, it is the 'real world', the only one apprehendable to Boku, the one in which he feels himself to be embodied. It is only as the coincidences between the two narratives start to accumulate, librarians and skulls in each, that we start to suspect a relationship between the two worlds, a relationship that would contest one or the other's claim to being a normal everyday reality, to being 'out here'. 
The relationship between the two worlds is discovered during a passage in the HBW narrative. At the most explanatory point of the novel, Watashi has travelled through an underground passage to meet with the Professor, the person who seems to have begun Watashi's problems, in order to seek answers as to what precisely has been done to him in order to make him such an attractive target of dangerous organizations:

“This prompted me t'hypothesize. What would happen if you fixed a person's black box at one point in time? If afterwards it were t'change, well, let it change. But that black box of one instance would remain, and you could call it up in just the state it was. Flash-frozen, as it were."

"Wait a minute. That would mean two different cognitive systems coexisted in the same person."

"You catch on quick," said the old man... "You'd have a stopped watch in your right pocket and a tickin' watch in your left. You can take out whichever you want, whenever you want."

And:
"We successfully rendered a computer visualization from your black box...I hit upon the idea of installin' another separate circuit to the junction boxes in your brains. Make it a three-way cognitive circuitry. And into this third circuit, I'd load my edited version of your core consciousness."

So Watashi has three cognitive systems operating on the subconscious level: the first the natural one we all possess, the second the 'flash frozen' one, and the third the visualised and edited version of the second. Through these quotations and other hints, the presence of the stopped clocktower and the name the Professor has given to Watashi's edited consciousness creation, 'The End of the World', impart the 49| P a g e 
realization that the narrative that Boku inhabits is the time stopped cognitive system that the Professor has installed into Watashi's head. Even though these proceedures may seem like bad science both in a technical sense as Murakami carefully avoids the technical details of where this 'black box' of consciousness lies, and ethically as the Professor's arguments throughout this section of the novel of curiosity for curiosities' sake become thin with repetition, we now know what we have been reading in the EotW sections is the representation of Watashi's core consciousness. From chapter twelve onwards, after Watashi has undergone the shuffling process, we know that that narrative is the representation of the third circuit, the Professors' edited version of Watashi's consciousness. This is evidenced in the narrative of EotW as it does change at this point, albeit very slightly: from now on there is slightly more cohesion in the narrative sequence than there was before as causal links are given between paragraphs and descriptions of 'a day in the Town' become the passages of specific days within that world, the result of Watashi's circuits being switched onto the edited narrative that the Professor has implanted. The end result of the Professor's tinkering with Watashi's brain is that soon Watashi's conscious capacity will no longer operate in this world, but he will inhabit that timeless loop of sub-consciousness, he will effectively 'live' within his brain-mind's black box. This is important as, emphasising Watashi's position as 'Everyman' for a moment, we can take the Professor's reasoning and character as Murakami's characterisation of the methods and morals of the scientific process with regards to sciences of the brain, the Professor here the personification of science. As already noted, however, the HBW narrative is not simply a morality play or allegory of modern life and such a reading, while being kept in mind, must be resisted as it is an interpretation that devalues the links between the two narratives, where the peculiarities of the way in which Watashi as an individual has formed the rich and imaginative subconscious realm of EotW, that realm which will be of so much importance as evidence for the workings of the brain-mind. The above passeages and subtle changes in the EotW narrative also give readers the evidence needed to retrace the changes in the EotW narrative in a way that provides more $\mathbf{5 0 | P}$ a g e 
connection between the two narratives, the interactions between which inform the model of the brain-mind which is taking shape as the narrative progresses.

These details allow the world of the Town to be placed into the model under construction. It is an 'out there' space, where the protagonist's perception of being embodied within his world prevents him from understanding it is not a normal everyday one. As Boku begins to come to terms with what exactly a loss of mind means, however, he begins to understand that the sense of embodiment he has taken for granted may be flawed. In discussion with the Colonel, Boku's nominal caregiver as he becomes orientated within the Town and its rules, Boku tries to create ways in which he can use the surface behaviour of individuals as evidence for the mind, but runs into difficulty:

"But are you not being extremely kind to me? Seeing to my needs, attending my sickbed without sleep? Are these not signs of a caring mind?"

“No. Kindness and a caring mind are two separate qualities. Kindness is manners. It is superficial custom, an acquired practice. Not so the mind. The mind is deeper, stronger, and, I believe, it is far more inconstant." "From what I gather," I begin, "the mind is lost when the shadow dies. Is this not true?"

"It is." (p. 169-170)

As shown in this quotation, surface behaviour is not always an accurate indicator of the workings of the brain-mind. Just as in Zunshine's Theory of Mind model the body is a privileged but known to be sometimes untrustworthy source of information, Boku is here told that his searching for evidence of mind behind the Colonel's actions is a fruitless one. Practice and custom is described as going part of the way to constituting actions that we can mistakenly perceive to be evidence of mind, and creates a difficulty for Boku and readers trying to define mind in relation 
to the society and culture around it. This attempt to distinguish between mind, society and culture is shown to be a diversion by the end of the novel, however, as the brain-mind is shown to be the Town and therefore constituted of the society and culture that dwells within it. Boku comes to the realisation that he is an individual instance of the brain-mind that has created the Town, that the entire town and its inhabitants are his mind.

We have begun to allocate this realm a similar place in our classification system as we did Old Tokyo in our analysis of Tea, as it is distributed throughout the townsfolk, disembodied as it is not physical in the same way that an 'out here' space is comprised of everyday matter, yet immediately recognisable, and a discrete sphere. But at the climax of the novel we see that the Town is somewhat different to Old Tokyo. In the Town the emphasis on collective custom is shown to be subservient to that of the individualised brain-mind, even though that brain-mind thought of as belonging to an individual is an instantiation of the Town itself, the world of Watashi's subconscious. The fragment representing 'Old Tokyo' in Tea contains a hint of this same tension between brain-mind and culture in the suggestion that at some point in the future Yuki comes to the realisation that she is not a young man as she has been led to believe; the EotW narrative works out this tension in a much fuller way by showing the steps that Watashi takes as a newcomer in the Town, through journeys that lead him to become proficient in mapping and reading and finally to realise that his relationship to the Town is one in which he is both within, constituting and creating the whole of the Town, the true nature of the relationship between his sense of individualisation and his brain-mind's representation of the subconscious. The world of the End of the World is also different from the world of Old Japan as the latter is a construction of a culture seeking to recreate that what has been lost; with the disappearance of the physical reality of Japan to be a cultural nexus Old Japan had to be created in an artificial reality, while the EotW is the creation of a sole individual. Watashi's status as an Everyman figure, however, allows an interpretation of the Town as an instantiation 
of the way Murakami portrays the brain-mind to work in each person, and that instance is one which, in a similar way to Old Japan, a culture has been created where all have their place, all their role in the functioning of that culture.

Thus far the process of reading the two novels and creating a model that describes the relationships between the worlds represented within them has focussed on an agent's perception of where they are embodied and, as a result, shows clearly that the ability to perceive of a consciousness as embodied is an attribute of the brain-mind and a crucial element of models that describe its workings. The particular importance of an agent's perception of where their body is has discovered an emphasis on the interactions between society and culture and the brain-mind, as well as difficulties that arise as agents begin to understand the relationships between the different spaces they inhabit. Exploring these difficulties further will create a deeper understanding of that which constitutes and affects the behaviours of the brain-mind. 
PART TWO:

INTERACTION OF SPACES

Defining the different fictional worlds of the novels as spaces in which an agent's sense of embodiment changes in relation to everyday reality has created a relational model of those spaces. The climax of each novel contains an instance of interaction between spaces, and notably it is an interaction where the representation of the normal everyday world is substantially affected by the actions in spaces that are not the normal everyday reality, those spaces that are 'in here', 'in there' or 'out there'. These interactions that make possible the changing of the everyday by the not-everyday occur through the mediums of culture and symbolic representation, and the close reading of these occurrences in this section will show the importance of communication, language and other cultural practices to be critical in the model of the brain-mind being developed.

Examining the climaxes of the two novels while focusing on the notion of communication allows a fuller understanding of the way in which realms which inhabit different spaces in the model interact. Both novels draw attention to the problem of communication: in Tea, the problem of accurate and helpful communication is found in almost every line of dialogue as characters lie, misunderstand and pun their way through journeys and interactions in all the worlds represented. In Hard-Boiled Wonderland the problem is made known to us immediately in the first chapter as Watashi attempts to engage in a silent conversation with the woman in pink, where a reference to Marcel Proust has no apparent relevance to either the conversation already undertaken or the environment within which the conversation takes place. These instances of problematic communication cause a reader to become alert to the possibility of a perfect communication: in Hard-Boiled Wonderland that communication takes the 
form of music, although that communication is not between characters, it is between spaces. Having come into possession of an accordion, Boku has been attempting to recall music that he can play on it. That attempt is fruitless until near the very end of the novel:

\section{Danny Boy.}

The title brings back the song: chords, notes, harmonies now flow naturally from my fingertips. I play the melody again...The whole town lives and breathes the music I play. The streets shift their weight with my every move. The Wall stretches and flexes as if my own flesh and skin. I repeat the song several times, then set the accordion down on the floor, lean back, and close my eye. Everything here is a part of me- the Wall and Gate and Woods and River and Pool. It is all my self.

For the first time in the novel, we see the Town as a living creature: before this moment the town has been an object, a construct, a framework that has exerted a will upon those inhabiting it, but at the moment that Boku realises his correct relationship to the Town, that it is a representation of his own 'self', the air of rigid unbendingness dissipates as the Town exhales and moves, shedding the dangerous force described in previous parts of the novel, no longer a place that is feared and fought against by those about to be assimilated. Important to note, however, is that the Town itself has not changed: it is Boku's perception of the Town that has been changed through the act of music and melody and has led him to be able to accept and own the dangerous parts of the Town and the apparently separate objects and agents as being 'all my self', but the physical representation of the Town after this moment of movement remains unchanged. As this moment allows Boku to understand that the town and its inhabitants are all a part of his own brain-mind, there literally occurs a moment of enlightenment as the skulls in the library awaken into a phosphorescent glow, and to where the Librarian's mind is to be found. As Boku is trying to find the mind of his Librarian among the unicorn skulls of the $\mathbf{5 5}$ | P a g e 
library, Watashi, also in the company of a Librarian, finds that his unicorn skull, a plaster replica created by the Professor from the images of Watashi's subconscious, is glowing.

So far throughout the novel, there have been coincidences and similarities between the two narratives, the presence of a Librarian and unicorn skulls, along with instances of events, such as the tune 'Danny Boy', occurring in both. These are explained by the everyday real world of HBW impacting the sub-conscious EotW: something that has already been shown to be possible in the world of the novel through our discussion of the Professor's experiments, and also something that we have less trouble in accepting as the relationship of 'out here' to 'in here' must always exist and is continuously occurring via our senses. But that events occurring in the realms of 'in there' and 'out there' could impact directly on the everyday without intermediary goes against common sense and the logic of the novel so far.

Thinking of the skulls of the Town as symbols, an association suggested by the fact that the skulls reside in a library, not a museum, and that Boku's job as newcomer is that of a reader, albeit of dreams, allows an understanding of this event. Contained within the skulls are fragments of minds that the beasts have been transporting to the outside of the wall of the Town each day, and it is the Dreamreader's task to read out the remnants of those minds after the death of a beast. Calling this act 'reading' imparts to it a sense of interpretation: that which anyone does to convert the black symbols on white paper into the meaning of a word, sentence and narrative is comparable with the act of Dreamreader extracting the sensations and images of a mind from the dream of a skull. Boku's journey to become a proficient Dreamreader begins with an apprehension that there is meaning in the images of the old dreams, and finishes when he is proficient at drawing out that meaning and is able to interpret it in order to achieve a goal. Just as we pick up a novel with some purpose in mind, even if that purpose is simply entertainment, reading is an act that takes on more significance as the one performing that act becomes aware of their process in that performance. For Boku 
as he reads the skulls in this passage it is the understanding that he will be able to find his Librarian's mind. The act of reading book or skull without that awareness of what can be obtained via that performance cannot generate the kind of knowledge that can be used as a tool in order to make a difference in the world as the process of conscious interpretation delves deeper into connections than a cursory look can. Boku's reading is successful and by placing old dreams and language together conceptually the glowing of the fake skull created as a strange joke by a rather eccentric professor is understood not as a freak occurrence of the non-physical affecting the physical without a medium, but one precipitated and carried forth by a language, in this case not a usual one, language being the vehicle that has already been suggested by the first chapter as, although not infallible, integral in the creating and accomplishing the processes of the mind.

In Tea a similar conceptual joining is that which places the hotsuit as synonymous with language, that medium that allows the machine to directly converse with the human. As Konstantin has moved her way through the AR world of the Sitty attempting to gain the clues that will solve her murder investigation, her experiences with the avatars of other human participants and help utilities have been confusing as she attempts to reconcile the language of 'in here' with what she is accustomed to 'out here'. The epiphany that allows her to crack her case, however, comes when Konstantin enters into sensory communication with a catalogue that relays the experiences of the murder victims directly through the hotsuit, the first of which is the drowning of a dragon, the avatar of Sally Lefkow:

A moment later, she was seeing things from the dragon's point of view, riding along in the footage. The experience was dizzying, almost incoherent...Briefly the vitals readings became visible on the screen; the numbers meant nothing to Konstantin but she didn't need them to feel the physical sensation of Sally Lefkow's panic at sensing something alien moving inside her skin, handling her person, manipulating her body.

(p.236-237) 
The sense of 'riding along in the footage' is disconcerting particularly because of the levels of embodiment that remove Konstantin from her everyday reality. She is at first remove inside $A R$, then inside the avatar she has been using to carry out her investigation, then Konstantin inside the avatar in placed into the footage of a murder, which she experiences from within yet another avatar. Also, although Konstantin is in the position to understand that this is only a representation of the murder, the force of that representation as it communicates the physical sensations of Sally directly to her nerves and synapses overrides both this knowledge of experience as representation and causes a physical response in Konstantin's own body: after experiencing the representation of the drowning for herself Konstantin's mouth salivates mucus as, although her body is now safe on artificial ground her brain-mind cannot help but react and cause physiological responses. It is this experience of communication between machine and brain-mind that allows Konstantin to finally move from believing in the absolute division of AR's 'in here' realms and her normal everyday reality to understanding the deep ways in which those two spaces communicate and influence each other. A way of thinking that encompasses the understanding of that communicatory process makes the idea of acts such as murder crossing that divide between 'in here' and 'out there' that much more tenable: whether the order to execute has the same responsibility for a death as the hangman's noose or not, it is understandable that language has a huge and often under-appreciated effect on the real world, and allows us to understand effects that the language of the hotsuit can have as machine speaks to body and brain-mind.

The above discussions illustrate concerns that occur within both novels around what will happen to us as humans as the discoveries of Cognitive Science begin to make it more possible for us, and in some cases may force us, to engage in processes that change perceptions of the relationship between the brain, mind, fiction or spaces that are understood to be constructed and able to be affected, and reality which is not thought to be constructed and malleable in the way that fiction 
is. As the novels progress they increasingly place strain on the understanding of the relationship between reality and fiction as one characterised by opposition, and the epoch of each is situated within an act that changes the perception of that relationship for the agents of the novels. This relationship we have for some time understood as one that has been able to change. The example of reading is an apt one, an everyday activity that changes the way we perceive ourselves to be embodied; during the act of reading we are 'in here', as the experience while taking part in a narrative we know to be constructed is qualitatively different from our experiences in the normal everyday world. In this way the reading just performed has given us a model with extremes within which we can situate various activities, both real and fictional, the assumption being that since both real and fictional events can inhabit the same place on the model there is less to distinguish between them than an oppositional model would suggest. 
PART THREE:

\section{THE BRAIN-MIND AS AFFECTED BY AND AFFECTING CULTURE AND SOCIETY}

Where particular concerns about the effects of the interaction between scientific innovation, society and culture, and human consciousness are elucidated within these novels occurs at places in the narrative where we can trace the influence of society and culture on the brain-mind, and vice versa. The way in which the brain-mind is affected by society and culture traces concerns relating to personal autonomy and choice in the science and technology dominated societies of the novels, characterised by the System and Factory in Hard-Boiled Wonderland and in Tea by the social restraints of AR. Opposing the concerns of the decline of personal autonomy are the apparent ways in which the brain-mind can affect society and culture, shown in AR post-apocalyptic world of the Sitty by that space's promise of being a realm where 'anything goes' in which superficialities can be infinitely manipulated ${ }^{21}$ and in Murakami's novel through Boku's eventual realisation of the true nature of the Town as being a part of himself and the relation that the Town has to the 'out here' reality that Watashi inhabits. The sections of the novels discussed below therefore trace the concerns resulting from the interaction of scientific and technological innovation on the individual through culture and society, and as a result discover the authors' opinions on what the sciences of the mind should strive to accomplish, and what those sciences should avoid.

21 For a discussion of how Cadigan's AR space reflects a stereotypical landscape of older cyberpunk fiction see Sponsler, Claire. "Beyond the Ruins: The Geopolitics of Urban Decay and Cybernetic Play". Science Fiction Studies, Vol. 20, No. 2 (Jul., 1993), pp. 251-265. This adoption of an artificial space to provide an escape from functioning society works well with the motif of escape discussed in Murakami's novel. Cadigan may have had the post-apocalyptic AR scenarios as the most popular for the practitioners partially as an inside joke for those familiar with the conventions of cyberpunk, but it nonetheless shows the need humans have of a knowingly constructed and nonreal space. 
As shown in Murakami's novel, the agent who ultimately has power over the brain-mind is the self, but this power is only achievable in a way that is so completely framed, so walled off, by societal pressures that that power can only manifest itself in a very simple choice: submit to those pressures, or run away. The existence of the Town is an allegory to this point, where the place that Boku is attempting to leave, before he apprehends the true nature of the Town, is literally encased in a Wall to which is given power beyond that of any normal everyday enclosing structure. Escape is the constant narrative drive throughout the novel, in both the narratives of EotW and HBW, escape from what is not understood but is absolutely encompassing. Watashi runs from enemies as Boku searches for an exit from the Town: the Professor we last see in a subterranean cavern surrounded by monsters in an attempt to place himself beyond the grasp of the System and Factory. Watashi's last act is one of acceptance as he slips into a coma-like state in a rented vehicle, pushed from the normal everyday world by the technology of a corporation that has controlled all aspects of his life. Boku's final choice after finding his own and the Librarian's mind is one that sees him stay within the Town, a society of his own creation, a choice fuelled by a sense of responsibility towards those parts of him that nonetheless also control him. The brain-mind is affected strongly by the society and culture it is embodied in, but it is an agent's final choice whether to stay and submit to those societal pressures or to escape. The very first scene of the novel, with Watashi in the elevator, sets up this motif of enclosure and reaction to that enclosure:

This elevator was so spacious it could have served as an office. Put in a desk, add a cabinet and a locker, throw in a kitchenette, and you'd still have room to spare. You might even squeeze in three camels and a midrange palm tree...I strained to hear something, anything, but no sound reached my ears. I pressed my ear against the stainless-steel wall. All I managed was to leave an outline of my ear on the cold metal...I tried 
whistling Danny Boy, but it came out like a dog wheezing with asthma.

In this passage Watashi's reaction to this 'hermetically sealed' elevator into which no sound nor meaning can penetrate is to begin creating meaning for the space himself. The images he colonises the elevator with are eclectic, ranging from urban office to desert dwelling, remembrances of the escapes of Houdini to comparisons to still life painting. Finding no stimulus for his brain-mind from his surrounding save the spaciousness of the elevator and its complete soundlessness Watashi uses all his senses to attempt an exploration of the space, only to fail and find what he has become accustomed to returned to him in ways that he can "hardly believe issued from my own body" (p.2), a melody transformed into the sounds of a sick dog. That we encounter the protagonist in this setting from the very outset of the novel is of importance: any elevator, but this elevator which has no controls and gives no sense of movement in particular, is a space outside the normal everyday reality; a space which travels between spaces that displaces the sense of embodiment and dislocates the brain-mind from its usual continual stimulation by the society and culture it is embodied within. Although not concerned with escape, Watashi's acceptance of his position as being out of his control at this point is yet another example of his stoic indifference towards otherwise disturbing events, the space of the elevator is an all encompassing and controlling environment that tests the metaphor making capabilities of the brain-mind through its very lack of stimulation.

The example of the elevator as a space that controls is complemented by the existence of the System and the Factory. In Watashi's world, the System is a gigantic corporation in the business of safeguarding and controlling the movement of information, the Factory an organisation that seeks to steal and disrupt those flows of information for its own monetary gain. As an operant for the system, Watashi employs learned automatic information encoding practices, called 'washing' and 'laundering,' that use the particular differences between the left and right 62|P a g e 
hemispheres of the brain to produce information scrambled in a way that can only be decoded by himself; he is also one of the few operants with the ability to 'shuffle', where the information is scrambled by being passed through the subconscious. The Factory has developed ways in which, by removing the brain from an operant, they can successfully decode laundered data, but are as yet unable to reverse the shuffling process. It is difficult to retire from the System as the System is afraid that their operants will then find work with the Factory, whereas infringement of the System's rules may lead to expulsion, a policy that Watashi wryly notes may be ineffectual as agents treated in this way almost always join the Factory's ranks. As Watashi's world stands, the System and the Factory control much of his life as, even before he became an immensely valuable asset to both sides by dint of the shuffling technology he is able to utilise, life was based around not drawing the attention of either organisation, either in a way that would result in expulsion or that could make him a target.

The sway that the System and the Factory hold on Watashi's life is comprehensive, although not complete; until the suggestion made by the girl in pink that the System and Factory may be the same operation, run by the same person (p.229). The shift from two competing entities to an entity that acts like two in order to exercise control seals Watashi within its power. No longer is the possibility of escape by defection possible as the organisation has completed its seal of power around Watashi: the only possible way out of his situation is the acceptance of the process that is about to take place because of the experiments performed on Watashi's brain by the Professor. At a specified time, Watashi's ability to experience the normal everyday world of HBW will fade as his consciousness becomes permanently embodied within the End of the World.

The complete power that the System and Factory have to influence the normal everyday world and the chaotic effects of their influence is mirrored by the professed perfection of the Town. In both narratives these powers are perceived to be absolute and the constant refrain of completeness and unchangability in both 63|P a g e 
gives their societal influences the same degree of power. The Town, of course, is shown to be differently constructed to that of the city produced by the societal pressures found in HBW. As Boku re-evaluates his relationship to the Town and discovers it to be a sealed elevator of his own, rather than others', creation, which leaves open the possibility that Boku is in a position to influence and change it. This realisation of responsibility towards the Town as his own societal creation is contrasted with the societal creation of the System and the Factory where there is ostensibly no agent with responsibility for those constructs known to either Watashi or the reader, as they are so large and powerful that they have gained their own inertia, rolling behemoths unstoppable. The end of the novel can be read then as a decision for a more responsible relationship in terms of the brain-mind and society, although it seems as though this might be possible only in a space that is known to be constructed, fictional, a reality with extra qualifiers, as the End of the World and the Town are, after all, solely constructs of Watashi's brain-mind.

This is only a negative conclusion if you believe that fiction has no power, either in its own world or the 'everyday real world'. The suggestion that a more responsible relationship between self and society, one where an individual agent has power to affect change, is only possible in fiction affirms the power of fiction as a crucial ability of the brain-mind. As shown throughout both novels, these fictions are a necessary underpinning and can affect the 'real-word' in significant ways, as a murder within AR can have effects on a real-world user or can be used as a space to accommodate a culture that has lost its physical centre, and a sub-conscious construct can provide escape from overbearing societal pressures. It is then tempting to collapse this equation and say simply that the individual does have power in the world, but to remove fiction from the equation would diminish the realisation that this power is only accomplished through fiction, the point that the novels labour and critics such as Porush, who place fiction and the interpretation of fiction at the centre of their processes of investigation, would agree with: the power 
of fiction is world changing, and perhaps the sole way in which we understand and affect that change.

This power of fiction to change the world in real ways is shown in Tea through Yuki's final transformative act as part of a bunraku performance, taking the place of the life-sized puppet that would usually be controlled by a team of puppeteers, and recreating the myth of Susanoo and Amaterasu. It is Yuki who must perform this action as it is Tom in this retelling of the myth, rather than Amaterasu, who needs to be brought out from the cave of hiding and put an end to the endless night of the Japanese culture through the dawning of Old Japan, the recreation of the Japanese culture's nexus, the Japanese people's 'source.' As Yuki is controlled by the ningyozukai, the puppeteers, she feels:

how she and the three puppeteers got out of synch with each other and instead of moving together, moved at odds. The four of them might have melded into one entity, a creature that could only be the product of a certain kind of joining...Her movements became more rhythmic. She was performing a dance now, she and the puppeteers, except she couldn't even really feel them anymore. She started to reach out her awareness for them and thought better of it- in this bunraku, the puppet was not supposed to remain conscious of the puppeteers, but enter a state in which its life was the combination of the puppets movements and the audience willing to let it be alive in their eyes.

(p.239...240)

Retelling a myth through the medium of bunraku, Yuki has become controlled by others and part of which controls them: the puppeteers may be able to move the puppet, but are restricted as to how they can move it by the puppet's joints and range of motion. As an allegory of the way that an agent is affected by and affects culture and society this performance of bunraku is particularly apt: Yuki is not simply a puppet, but a conscious entity that is able to decide to flow with or resist the controlling influences around her. In this example all participants are working towards the same end, the recreation of a myth, which further enhances the status 65| P a g e 
of this act as one constituted by a larger framework of cultural understanding. Also, it is a performance that takes place in front of an audience, an audience that participates not just as spectators but as those who join in the dance and chant that is the bunraku's climax. The result of this successful bunraku is the creation of Old Japan. As stated earlier in this chapter, Old Japan is a space with the qualification of 'out there', that is that Old Japan is a world in which only those with privileged knowledge such as a reader, those outside the world of Old Japan, would be able to identify as not 'out here', not a normal everyday reality. Considering the hypothesis that this could be said of any space, that any 'out here' is only considered to be so because an agent embodied within that space has no knowledge that it could be, or is, otherwise to that sensation of embodiment, then what this retelling of a mythical fiction through dance has achieved is the creation of a world.

These fictional constructions which have the power to affect change in the normal everyday world carry the important qualifier of being authored by an agent. The Town is an unconsciously created fiction of an agent, whereas the Sitty is consciously authored by all who interact within it. Both constructs take on more power as they are known to be the result of an authoring process and in this way are differentiated from models of the brain-mind that use cultural and physical evolutionary theory as the core of their models, such as the models created by Zunshine and Torey. The emphasis on evolution for creating the processes and spaces that the brain-mind interacts with and within, however, devalues the process by which an individualised brain-mind can also create and affect spaces which the novels realise. It cannot be said that Watashi's subconscious creation, the Town, is only created by a society and culture epitomised by the System/Factory which is as unchangeable as the path of evolution taken, nor are Yuki's acts that re-establish a space for the culture of Old Japan possible without Yuki's own connection with Tom which leads to the discovery of the 'out door.' Both events within the novels are shown to be the result of a complex interaction between societal and cultural knowledge, within which scientific knowledge about the brain-mind also resides, 
and personal autonomy which is both beholden to and influences those knowledges. Characterising the process of space creation, whether those spaces be in here, out there, in there or out here, as a process of authoring either by an individual instantiation of the brain-mind or by physical and cultural evolutionary processes brings back into the discussion the importance of representation.

The ability to represent spaces as part of the everyday real or as fictional construction is an essential ability of the brain-mind, especially as has been shown through the distinctions between 'out here' and 'out there'; how each space is represented is the only way to differentiate between them. The difference between Old Japan and our own reality is only that readers of the novel know one of these worlds as represented to us is fictional. This may suggest that the understanding of a space as either fiction or reality is a choice, but the point is rather that understanding is generated by the society within which an agent is embodied. Although we can comprehend that the world is represented to us through the senses, we know that the human eye can only process a minute portion of possible hues in the spectrum of light; as we are embodied within this space the constructs of society and culture that affirm its reality are comprehensive and leave little room to attribute the qualifier of 'fiction' to this world of sense. A world that we are able to orientate ourselves towards as embodied outside of everyday reality, however, is easily recognised as fictional. What the novels show is that since these spaces can be defined differently depending on where one feels oneself to be embodied.

The model of understanding the brain-mind that these novels have put forth can be understood thus: the brain-mind exists in and links together a number of locations, all of which can be described as lying in the area defined by the concepts of 'in here', 'out here', 'in there', 'out there', which describe the influence of conceptions like 'reality' and culture, and a perceived distance between the mind and reality, over the operation of that brain-mind while in a space. This perceived distance is characterised through how an agent operating in that space perceives themselves to be embodied, the strength of the quality of that embodiment, and the 67|P a g e 
degree to which that agent feels that the space they inhabit has been constructed. The more constructed a space, the more fictional, that is to say, different from but not opposing to spaces perceived as reality, and the ability of an agent to apprehend that space's constructed nature imparts more power through which that agent can affect that space. As this model generated from the novels is a relational one it traces the understanding of an agent as that agent affects and is affected by those spaces, and how spaces may be understood to affect and interact with other spaces. These interactions take place through the medium of language. Apart from the effects of embodiment and awareness of construction that an agent may have about a space, the model stresses the importance of society and culture upon the brain-mind. What these novels particularly demonstrate demonstrate is how a new science of cognition can change perception and therefore produce effects in this relational model: AR takes Yuki from the real everyday world and places her within a new world she cannot discern from everyday reality, whereas the construction of a fictional space in Watashi's cognitive basement provides the only means of escape. It is a model in which society and culture, Cognitive Science and technologies, and individual agents are shown to be in a delicately reciprocal relationship. Any place we can ascribe with certainty a number or range of the above attributes to is a space, and the spaces too share reciprocal relationship to each other that the aspects of the model show.

The model, although generated from reading of fictional texts is not limited to worlds within fiction as the distinctions of those worlds can be applied to normal everyday reality also, such as the change in embodiment we perceive when we read a book. This allows considerations of society and culture, along with specific instances of society and culture like Cognitive Science, to be thought of as those constructions which exist in any given space and interact with an agent. This model is especially helpful in positioning and relating the different realms that agents find themselves within and interacting with. Specifically, by applying this model to moments in the novels in which one realm has a direct influence on another, 
language and communication is shown to be the mediator between these different spaces and is therefore a crucial component of how we understand the brain-mind to work. Examination of these moments has also shown the extent to which it must be understood that the brain-mind is both affected by and able to affect society and culture. The novels have also shown that this reciprocal process of affecting/affected has the ability to create spaces, worlds, within that area of 'in here', 'out there' etc. in a fictional setting that can influence and impact upon the normal everyday worlds of those novels, suggesting that a fictional world, perhaps represented in a novel, can therefore also influence the normal everyday reality readers inhabit. Further examination of the role of language and representation within these novels will show the power of this model and what it can offer to our understanding of, and the goals of, Literature and Cognitive Science, as in the next chapter this model is further connected with the models discussed in the first chapter. 
CHAPTER THREE:

\section{CRITIQUE}

Having completed the process of generating models of the brain-mind from the evidence of the novels Hard-Boiled Wonderland and Tea the program of critique that was set down by Jan Slaby has already been sufficiently engaged with: the notion of examining an area of enquiry within the richness of its contexts has been accomplished in the last chapter by using the novels as a particular instance of writing concerned with the brain-mind, writing that this thesis is arguing must be kept in the conceptual frame of anyone engaging with the field of Literature and Cognitive Science in order for a comprehensive model of the brain-mind to be possible. Through the first chapter substantial groundwork has been laid towards the goal that Slaby characterises as the 'identifying of stakeholders', those that have the ability and the desire to affect the process examined in conjunction with the area of enquiry, performed as the field of Literature and Cognitive Science was introduced and the critics writing within that field and actively prescribing manifestos for future goals of the field were examined and positioned in relation to each other and the central aims of this thesis.

Returning to Slaby's program for critique, however, the notion of identifying stakeholders is the one which has had the least coverage in the previous chapter of this thesis as the examination of the novels took place. Slaby points to the need to not just examine how the process may be affected, but also as to how stakeholders are produced as such in the first place. In regards to literary fiction, three groups can be readily identified as stakeholders: novelists, readers, and literary critics.

To identify novelists and readers as stakeholders in the processes surrounding novelistic fiction, and by extension the field of Literature and Cognitive Science is, on the face of it, a trivial matter. Novelists write, readers read, and how this interaction 70|P a g e 
takes place is a core concern of the literary critic. Literary Critics are the generators of formal knowledge from literary texts, and have a rich history of that process within which to orientate themselves to various concerns relating to that process, although, as stated above, critics operating within the field of Literature and Cognitive studies have less of that history to rely on by virtue of the field being an emergent one, so necessarily those working within this field will also be aware of the need to present themselves as stakeholders, those who are in the process of defining a position. Against active knowledge of positioning that critics must work with, the position of reader and writer of a text would seem relatively simple, yet the characterisation of writer and reader as generator and consumer is too simplistic a description: as shown in the previous chapter, Cadigan and Murakami have created characters that themselves are in the process of both reading and creating their own environments, and becoming aware of that process, showing their actions to be constituted and impacted by society and culture and the scientific knowledge imbedded within society and culture and therefore representing the very process that we take for granted in this way: the transmission of knowledge is represented within the novels to be a complex process between agent and environment, formal knowledge and fiction, at the nexus of which stands the brainmind, that capability shared by all and felt to be instantiated as individual in each and every one of us as we use it to affect and constitute the surrounding environment. Shifting the emphasis from the representation of a brain-mind of a fictional entity such as the characters found within these novels to the interaction of a reader's brain-mind interacting with a representation of the processes of brainmind both again affirms the notion that the model of the brain-mind created through the examination of these novels can be used in analysing interactions in everyday reality as well as interactions within fiction and, therefore, provides evidence for the argument that these novels and novelistic fiction in general should be given status as rich sources of knowledge for the understanding of the brainmind. Examining this claim, therefore, it will be necessary to examine how the models generated by both the reading of the novels and the critics' models of brain71|P a g e 
mind agree and disagree, especially in regards to fiction's representational status, as it will be the understanding of the importance that can be placed on a representational text, in this case the literary fiction of the novels, which will provide the final emphasis in the argument for the inclusion of literary fiction in the contexts which bear upon Literature and Cognitive Science, but also affirm the value that the knowledge generated by critical analysis of such texts can have to the processes of Cognitive Science itself, and ultimately our understanding of the brainmind.

The status of fiction as a type of representation is not a new one, but there is sufficient weighting on the notion by the novels to give serious consideration to what happens when we take all representation to be fiction: certainly those of us who are students of literature are in a privileged position here as we have been trained to remember the mediating frame of the novel as a representational object, an artefact of brain-mind, affected by and affecting culture and society in all the ways in which the brain-mind can; what we all may have trouble with is accepting the notion, and its consequences, that not only can the brain-mind ever only be understood in representational terms, but also that the mind works and is constituted by representation.

The notion that we can only ever understand the mind in representational terms is borne out by the work of Porush, Zunshine and Murakami. Porush points towards understanding that the way we understand is built out of metaphor, itself a process of representation, by affirming that the brain-mind must reason that two things are one in order to compress and understand anything from irrational reality and turn it into applicable knowledge. Zunshine's Theory of Mind is sustained by evolutionary theory and neuroscientific discoveries to give a model that treats others' actions as representations of our own actions, agents that can be understood because we can combine their actions with the feelings and thoughts behind our own and project those feelings and thoughts onto other agents. Murakami's conception of the mind helps to further both these models because, for the 
characters within Hard-Boiled Wonderland and the End of the World, the only way that their own consciousness is understandable is via a representation. Watashi's subconscious mind was rendered into video by another, the Professor. The process of rendering consciousness onto video could well be taken as an analogue of the process that Zunshine describes in which through everyday interactions we render our own consciousness onto the actions of others: the Professor through the editing of a media visualisation is completing a real-world process that takes something of another and renders it into a form that can be understood, symbolically similar to the process that the mirror neurons undertake to create a thought-representation of another's actions. Against this process of 'rendering onto another,' however, Murakami's novel also posits the notion that functioning conscious agents also engage in the process of re-rendering their own consciousness in order to be able to gain understanding of their own conscious abilities and traits. Watashi has managed to create his own re-rendering of his internal world, that he was somehow able to 'descend to the factory floor' and take control of the elephant factory that is the Professor's metaphor for the mind creating process, a process that being described in such mechanical terms cannot help but recollect Porush's metaphor machine, where memories and knowledge are combined into ever more complex bundles that eventually create conscious systems. This ability to apprehend and understand the representational processes of his own brain-mind is what has made Watashi the only operative to survive the shuffling actualisation.

This is not a common occurrence in the novel. It is made clear that to have control over the elephant factory, the centre of the Theory of Mind, is very unlikely; Watashi's position as an Everyman character, however, suggests that the process of re-rendering one's own consciousness is in fact a possibility for all, and that Watashi is only an instance of the extreme to which this process may occur.

The engagement with one's own consciousness, to whatever degree of accomplishment, is only on and through representational terms. When Boku realises that the Town is a representation of his own subconscious, that the Town and its 73|P a g e 
inhabitants are creations of and constituents of his own brain-mind, that representation does not melt away into some sort of pure, un-rendered piece of conception; it retains its shape and form, the only conceptual shift being the reader's and Boku's apprehension of the substance of the place. Believing that Boku is that part of Watashi that was able to descend to the factory floor of the subconscious, the highlighting of the unchanging form of the Town at this moment is an important fact: if we were being asked to believe that the Town as an understanding of the brain-mind was an ultimately false one then that representation would have changed as its creator finally apprehended its true nature. That this change does not take place strongly suggests that the form of the subconscious as a representative rendering is a true one; the only possible fallacy is the one that conceives of the substance of such a rendering as not being of the brain-mind. Just as Zunshine's Theory of Mind could not operate seeing the actions of another agent as representative of the thoughts we would have in order to perform that action, Murakami affirms that we cannot apprehend our own mind except through a representation.

This realisation goes hand in hand with Zunshine's emphasis on the neuroscientific discovery of the mirror neurons, those clusters of neurons within the brain that react the same way in the brain when an agent performs an action and we view an agent perform that same action. To Zunshine the consequence of this is that, at the neuronal level of our brain where the mirror neurons reside, there is no difference between our performing an action and our viewing another performing that action. It is this lack of difference in operation in the mirror neurons that Zunshine takes as the basis for her theory that, at that level of the brain, what you do is what I do. The reasons for my actions are the same as another's when that agent's actions are the same. Where Murakami's genius comes to the fore is in not assuming that the agent that is viewing another agent is in fact a different agent: the viewing of another performing an action is the same as viewing myself perform an action, and therefore there is little to distinguish between the two actions than where an 
agent feels themselves to be embodied. The importance of this 'sense of embodiment' has already been discussed as a tool to define spaces, but it is also important in the definition of an agent: the Town is Boku, trees, wall and inhabitants are all his own self. The reason the EotW narrative behaves the way in which it does is due to its embodiment within Boku. However, this embodiment could have taken place in any other character or object within the Town without changing the relation of the EotW to the HBW. Therefore, the position of ' $\mathrm{I}$ ' is arbitrary unless perceived to be otherwise: the placement of the embodiment of a mind within a space is not important, although the quality of that embodiment will change the perception of that space. This arbitrariness is supported by the behaviour of the mirror neurons as they do react in exactly the same way on both occasions of action and viewing of action, and eliminates the problems that arise from the assumption that the way that 'I' operate is different from the way that 'I' perceives others to operate. Although the Theory of Mind states that we can only know another mind through the representation provided by action or expression, this is less of a handicap when we believe that this is also the only way that we can know our own mind. Only from the observation of the action of thought do we build up a representation of a brain-mind, including our own.

Zunshine's emphasis on the body and the actions a body perform as a privileged source of knowledge is united with the knowledge that the understanding gained from that source can be sometimes misleading. This misleading quality of action that is used to create our understanding of the brain-mind allows for Boku's first misunderstanding the nature of the Town; if the observation of action alone built up a completely reliable representation of a brain-mind, whether others or our own, then it would be impossible for an agent such as Boku to misinterpret his surroundings as not of his own creation, for they would have been directly created from observances of past interactions. That there is much in the Town that is strange to Boku fits with the model given to us by Zunshine, is shown to work in 
representational ways as Porush affirms and allows for the capacity of imagination that must be included in any comprehensive model of the brain-mind.

The elimination of an agent's feelings of individualisation in order to further understand the workings of the brain-mind is not easily achieved, however, as the feeling of being and individualised agent embodied within a certain space been shown above to be in many cases the only indicator that that agent has in perceiving the difference between a fictional or real space, between an agent's self, other and constructed. When confronted with the hypothesis that an agent is indistinguishable from others and unable to distinguish environments save through perception of embodiment, a reasonable question to ask with the above statement is 'what does the observing' and 'what builds the representation?' The first question has been answered with mechanical explanations, those explanations which are primarily the goal of Cognitive Science as it seeks to provide understandings of how the brain takes sensory information to create mental experience we are familiar with, and there are a number of theories that endeavour to mechanically explain the second, explanations that deal with thought and memory with particular reference to the neuronal constructs of the brain. Murakami's conception of the brain-mind is one that is both representational in form and in substance, as the substance of the brainmind is shown through representations and forms meaning through representation. Focus on how representation is built in the brain-mind needs to be understood through models which support Murakami's conception by the creation of mechanically based models. The idea of a brain-mind shown to both work via acts representation and in some senses to be constituted of those acts is perhaps one that is the most incommensurable with more classic conceptions of the workings of the brain-mind, and yet Torey, Herman and Cadigan all provide models of how this might be possible and give different emphasis to this problem.

Both Torey's and Herman's conceptions of the working of the brain-mind include a process in which the brain-mind is made aware of itself and feeds back upon itself. Herman's model places this faculty as distributed beyond the physical 
boundaries of an agent; in Torey's the feedback is accomplished via the interaction between first and second tier neurons within a physical brain. Herman's model suggests the mind must be mediated by culture and society, amongst other things, just as the input to output part of the cycle is mediated by the brain. Both of these models contain a recursive aspect: Torey's model gives little emphasis on what becomes of the outputs of brain-mind and likewise to where the inputs may have come from; Herman's is accomplished only through the connection of mind and the material world. The truth lies within the gradient of these two extremes and that although none of us work and think in a vacuum we can believe that it is possible: that the mind is distributed in everyday matters, but even when we are trapped within a hermetically sealed elevator, ostensibly cordoned off from the everyday, the culture and society that was known still affects through its sudden absence. The extent to which the brain-mind is functioning at one or the other end of the spectrum of active engagement with or believed disengagement with the environment, society and culture would depend on a multiplicity of factors, and would be changeable moment to moment. Where the two novels disagree the most is also here at the deciding of how much weight to place on the role of the external: Murakami's conception of the brain-mind is largely one which is contained within a singular agent, where the belief of a brain-mind apart from society is high, although ultimately proven erroneous; Cadigan's conception is one in which the environment, society and culture sometimes seems violently intrusive, but is always part of, the workings of the brain-mind. Since we have already given Murakami consideration, we will now focus mostly on Cadigan.

The Artificial Reality of Cadigan's Tea from an Empty Cup is wrought from the tensions born of, on the one hand, the desire for individual autonomy and, on the other, the need for collective control. The fashions of the normal everyday world, such as facial hair as the new fad for females, is a somewhat more comical nod in that direction, but as motioned elsewhere, it is within the environment of AR that the real battle for power occurs, stemming from the above dichotomy. Certainly the 
greatest achievement is individual autonomy but that power is only achievable if one understands the places that one can exercise it within the collective. The individual can be as individual as one chooses but will always be the individual within the collective: as Body Sativa becomes the goddess for the arts Yuki assumes her place because "[s]omebody has to be Bodhisattva" (p.250). The collective cannot exist without, at least conceptually, agents playing certain roles and to participate in that collective each has to define their selves in relation to these concepts. The defining of the self in a negative way to a collective's core tenet does not in fact exclude one from that collective: an agent defining themselves in this way is then involved as an antagonist. Only absolute ignorance of a collective can grant absolute personal autonomy from it, and even then that society may be using the ignorant as concepts, creating space for the concept of outsider even as that outsider is unaware.

This finding of conceptual space within a collective is most noticeable in Konstantin's narrative as she is almost entirely ignorant of the workings, the society and culture of AR. For a place that promises absolute personal autonomy, the fact of collective control is exaggerated every time Konstantin interacts with another agent within the Sitty. If it is an interaction with a computer help utility, it is the role of language that is highlighted. The small difference in the workings of prescriptive, and pre-scripted, language used by these constructed utilities and everyday speech based on everyday shared understandings asks us to re-examine the role that language as knowledge plays. If language is thought of as another mode of symbolic representation, then the puns that are littered, almost chokingly, throughout the novel work as examples of the way in which certain representations can both help and hinder understanding. Puns work by exploiting the arbitrary relation between symbols, for example, the icon for hot link is a sausage en flambé, but through that arbitrariness can help us understand something of the nature of an object. The catalogue being represented as a cat speaks of the power of that object but also of its indifference, a creature tamed for a certain use that still retains part of its 
independence: an association that is first achieved by the arbitary taking of the first three letters of 'catalogue' but then affects the object in question. In the interactions that Konstantin has with the final catalogue that comes into her possession the issue of what holds the power, Konstantin or the object, is debateable, as although the catalogue obeys Konstantin's commands she is unable to escape the representations created by it. All appearances within this hyper-reality are symbols often arbitrarily constructed upon whim, but it is the manipulation of these apparently arbitrary representations that ultimately affect mind and world, both artificial and real, a possibility that both Herman's and Torey's models allow.

The way in which the characters of these novels are stakeholders in the production of meaning in their interactions with their environments is commensurable with the possibilities allowed by the models generated by the critics examined in the first chapter. These interactions that produce knowledge are also indicative of the way that other agents, such as writers, readers and literary critics, also produce knowledge through interactions with their environments, particularly through interactions with literary fiction. The status of the novels under examination as physical objects 'out here' and also representational of 'in here' spaces allows the process of reading, writing and interpretation to be mapped on the same model that has been created to gain insights from the narratives themselves, and therefore the act of engaging with a text carries similar qualities to the interactions that the characters of the novels perform. In this way it can be stated that the interactions that take place between agents, spaces, society and culture within a literary narrative can be used as evidence to support understanding of the interaction between agents, spaces, society and culture in reality. In this case these interactions have been examined regarding concerns of how the brain-mind can be said to operate, and the models generated by this process must be taken as crucial indicators of how the brain-mind operates, the central object of enquiry for Cognitive Science. 
Thusly, this thesis argues for and shows that the field of Literature and Cognitive Science must engage in the creation of models for understanding the brain-mind from Literature and affirm their importance as evidence as they are compared to the models that describe the brain-mind that are generated by research in the field of Cognitive Science. This comparison must take place in a way that does not simply use Literature as evidence of the descriptions generated by Cognitive Science, but put forth models generated through the examining of Literature in relation to the brain-mind as having evidentiary value especially when those models explore aspects and issues that are not the concern of Cognitive Science. This process of comparison is the manifesto for the field of Literature and Cognitive Science that this thesis affirms, the final part of the process that Slaby puts forth in his notion of critique: the critique performed in this thesis on the field of Literature and Cognitive Science, and what emphasis is to be placed on literary fiction within that field, is expected to inform practice within that field and, with hope, the field of Cognitive Science itself, either in the processes of research or the process of critique surrounding it. 
This thesis is an examination of the emergent field of Literature and Cognitive Science, as well as being both a contribution to that field and a critique that generates discussion around how that field may be developed in the future. By taking a representative set of critics' work the field of Literature and Cognitive Science has been shown to be a field that can encompass a large array of approaches as critics both have the multifarious disciplines of Cognitive Science and of the Humanities to use as inspiration in their interpretive work, and also allows the participant within the field of Literature and Cognitive Science to place emphasis in their work along a continuum of approaches between literary interpretation and integration of scientific practices. The thesis has then used the concerns and models that were generated by the examination of that critical work to engage in the interpretation of two modern novels, a process that has generated models of understanding the brain-mind, undertaking its own critical process to generate formal knowledge from literary narrative. The knowledge generated by the process of literary interpretation has then been shown to be commensurable with the summary of knowledge presented by the critical work examined in the first chapter, and by examining the ways in which these knowledge frameworks enhance and differ from each other in emphasis has created a manifesto for areas that must be given further emphasis in the field as a whole. In particular, the influence that culture and society has on the brain-mind as a distributed entity as shown within the literary narratives examined is shown to be possible within the models produced by the critical writings but not given the emphasis that the novels themselves do. By affirming the mimetic and evidentiary status of literary narrative to be shown through representational acts that can be qualified in the same way as acts in the real, everyday world, the ability of literary narrative to both present and explore the workings of the brain-mind in a non-scientific way has been shown to be one that can provide a rich resource for the generating of understanding of the 
brain-mind in ways that affect and are commensurable with understandings of the way that the brain-mind works. This process of generating understanding must be incorporated into the way we understand the brain-mind to work, and can be said to be one of the crucial processes that need to be undertaken in the field of Literature and Cognitive Science, in order to create a rich interaction of critique between those of the Humanities, particularly those engaged with Literature, and the practitioners of Cognitive Science and the knowledge generated by that endeavour. 


\section{BIBLIOGRAPHY:}

Alan, Richardson. "Literature and the Cognitive Revolution: An Introduction." Poetics Today. Vol. 23, No. 1, 2002, pp.1-8.

Cadigan, Pat. Tea from an Empty Cup. New York: Tom Doherty Associates, 1998.

Calvino, Italio. T Zero. New York: Collier Books, 1970.

Choudhury, Suprana, Saskia Kathi Nagel and Jan Slaby. “Critical Neuroscience: Linking Neuroscience and Society through Critical Practice." Bio Societies. Vol. 4, 2009, pp. 61-77.

Dennett, Daniel C. “Quining Qualia.” In: Marcel, A. \& Bisiach, E. (eds.) Consciousness in Modern Science. Oxford University Press, 1998.

Dill, Jonathan. Murakami Haruki and the Search for Self Therapy. University of Canterbury, 2008. <http://hdl.handle.net/10092/1004>

Fludernik, Monika. Towards a 'Natural' Narratology. London: Routledge, 1996.

Grishakova, Marina. "Beyond the Frame: Cognitive Science, Common Sense and Fiction." Narrative. Vol. 17, No. 2, 2009, pp. 188-199. 
Herman, David. Ed. Narrative Theory and the Cognitive Sciences. California : CSLI Publications, c2003.

Herman, David. "Storytelling and the Sciences of Mind: Cognitive Narratology, Discursive Psychology, and Narratives in Face-to-Face Interaction." Narrative Vol. 15, No. 3, 2007, pp. 306-334.

Heuser, Sabine. "(En)gendering Artificial Intelligence in Cyberspace." The Yearbook of English Studies. Vol.32, No.2, 2007, pp.129-145.

Latour, Bruno. "Why Has Critique Run out of Steam? From Matters of Fact to Matters of Concern." Critical Inquiry, Vol. 30, No.2, 2004, pp. 225-248.

Mitchell, Kaye. "Bodies that Matter: Science Fiction, Technoculture and the Gendered Body." Science Fiction Studies. Vol. 33, No.1, 2006, pp. 109-128.

Murakami, Haruki. Hard-Boiled Wonderland and the End of the World. London: Vintage, 2003.

Porush, David. "Cybernetic Fiction and Postmodern Science.” New Literary History, Vol. 20, No.2, 1989, pp. 373-396.

Porush, David. “Hacking the Brainstem: Postmodern Metaphysics and Stephenson's SnowCrash." Configurations, Vol. 2, No. 3, 1994, pp. 537-571. 
Porush, David. "Voyage to Eudoxia: The Emergence of a Post-Rational Epistemology in Literature and Science." SubStance, Vol. 22, No. 2/3, Issue 71/72: Special Issue: Epistémocritique (1993), pp. 38-49.

Rubin, Jay. Haruki Murakami and the Music of Words. London: Vintage 2005.

Schrödinger, Erwin. What is Life?: the physical aspect of the living cell. New York: Cambridge University Press, 1944.

Slaby, Jan. "Steps Towards a Critical Neuroscience” 2010. 5 March, 2010.

< http://www.janslaby.com/pubs/Slaby_StepsTowardsCNS_2010.pdf>

Snow, C.P. “The Two Cultures.” Leonardo, Vol. 23, No. 2/3, 1990, pp.169-173.

Sponsler, Claire. "Beyond the Ruins: The Geopolitics of Urban Decay and Cybernetic Play". Science Fiction Studies Vol. 20, No. 2 (Jul., 1993), pp. 251-265.

Strecher, Matthew C. "Magical Realism and the Search for Identity in the Fiction of Murakami Haruki." Journal of Japanese Studies. Vol. 25, No. 2, 1999, pp. 263-298.

Takagi, Chiaki. "Third Space Wonderland and the End of the Modern: Representation of Tokyo in the Works of Murakami Haruki." Southeast Review of Asian Studies. Vol. 32, 2010, pp. 193-198. 
Torey, Zoltan. The Crucible of Consciousness: an integrated theory of mind and brain. Cambridge, MA : MIT Press, 2009.

Torey, Zoltan. “The Immaculate Misconception.” Journal of Consciousness Studies. Vol. 13, No.12, 2006, pp. 105-110.

Williams, Raymond. The Long Revolution. Great Britain: Broadview Press Ltd, 1985.

Zunshine, Lisa. Ed. Introducton to Cultural Cognitive Studies. Maryland: The Johns Hopkins University Press, 2010.

Zunshine, Lisa. "Theory of Mind and Fictions of Embodied Transparency.” Narrative. Vol. 16, No. 1, 2008, pp. 65-92.

Zunshine, Lisa. Why We Read Fiction: Theory of Mind and the Novel. Columbus : Ohio State University Press, 2006.

$86 \mid \mathrm{P}$ a g e 